Federal Reserve Bank of Minneapolis

Research Department Staff Report 417

November 2008

\title{
Sluggish responses of prices and inflation to monetary shocks in an inventory model of money demand*
}

\author{
Fernando Alvarez \\ University of Chicago \\ and NBER
}

\begin{abstract}
Andrew Atkeson
University of California, Los Angeles, Federal Reserve Bank of Minneapolis, and NBER
\end{abstract}

\section{Chris Edmond}

New York University

and University of Melbourne

\begin{abstract}
We examine the responses of prices and inflation to monetary shocks in an inventory-theoretic model of money demand. We show that the price level responds sluggishly to an exogenous increase in the money stock because the dynamics of households' money inventories leads to a partially offsetting endogenous reduction in velocity. We also show that inflation responds sluggishly to an exogenous increase in the nominal interest rate because changes in monetary policy affect the real interest rate. In a quantitative example, we show that this nominal sluggishness is substantial and persistent if inventories in the model are calibrated to match U.S. households' holdings of M2.
\end{abstract}

\footnotetext{
*A previous draft of this paper circulated under the title "Can a Baumol-Tobin model account for the short-run behavior of velocity?" We would like to thank Robert Barro, Michael Dotsey, Tim Fuerst, Robert Lucas, Julio Rotemberg, and several anonymous referees for helpful comments. For financial support, Alvarez thanks the NSF and the Templeton Foundation and Atkeson thanks the NSF. The views expressed herein are those of the authors and not necessarily those of the Federal Reserve Bank of Minneapolis or the Federal Reserve System.
} 


\section{Introduction}

In this paper, we examine the dynamics of money, velocity, prices, interest rates, and inflation in an inventory-theoretic model of the demand for money. ${ }^{1}$ We show that our inventory-theoretic model offers new answers to two important questions: why do prices respond sluggishly to changes in money? and why does inflation respond sluggishly to changes in the short-term nominal interest rate? We first show analytically how prices and inflation are both sluggish in our model, even though price setting is fully flexible. We then show through a quantitative example that this sluggishness is substantial and persistent when our inventory theoretic model is interpreted as applying to a broad monetary aggregate like M2.

Our model is inspired by the analyses of money demand developed by Baumol (1952) and Tobin (1956). In their models, households carry money (despite the fact that money is dominated in rate of return by interest bearing assets) because they face a fixed cost of trading money and these other assets. Our model is a simplified version of their framework. We study a cash-in-advance model with physically separated asset and goods markets. Households have two financial accounts: a brokerage account in the asset market in which they hold a portfolio of interest bearing assets and a bank account in the goods market in which they hold money to pay for consumption. We assume that households do not have the opportunity to exchange funds between their brokerage and bank accounts every period. Instead, we assume they have the opportunity to transfer funds between accounts only once every $N \geq 1$ periods. Hence, households maintain an inventory of money in their bank account large enough to pay for consumption expenditures for several periods. They replenish this inventory with a transfer from their brokerage account once every $N$ periods. As households optimally manage this inventory, their money holdings follow a sawtooth pattern — rising rapidly with each periodic transfer from their brokerage account and then falling slowly as these funds are spent smoothly over time - similar to the sawtooth pattern of money holdings originally derived by Baumol (1952) and Tobin (1956), and more recently by Duffie and Sun (1990) and Abel, Eberly, and Panageas (2007). Here, we focus on the implications of our model for the response

\footnotetext{
${ }^{1}$ Traditionally, the literature on inventory-theoretic models of money demand has focused on the steadystate implications of these models for money demand (for example, Barro 1976, Jovanovic 1982, Romer 1986, Chatterjee and Corbae 1992). Here we examine the implications of an inventory-theoretic model of the demand for money for the dynamics of prices and inflation following a shock to money or to interest rates.
} 
of prices to a change in money growth and the response of inflation to a change in interest rates. To highlight the specific mechanisms at work, we make the stark assumptions that price setting is fully flexible and that output in the model is exogenous so that our results can easily be compared to those from a flexible-price, constant-velocity, exogenous output benchmark cash-in-advance model of the effect of monetary policy on prices and inflation.

Our first result is that prices respond sluggishly to a change in money in our model. Prices respond sluggishly in our model because an exogenous increase in the stock of money leads endogenously, through the dynamics of households' inventories of money, to a partially offsetting decrease in the velocity of money. As a result of this endogenous fall in velocity, prices respond on impact less than one-for-one to the change in money. Prices respond fully only in the long-run when households' inventories of money, and hence aggregate velocity, settle back down to their steady-state values. The sluggish response of prices to a change in money in our model can then be understood not as a consequence of a sticky-price setting policy of firms but as a simple consequence of the sluggish response of nominal expenditure to a change in money inherent in an inventory-theoretic approach to money demand.

We highlight this implication of our inventory-theoretic model of money demand because a strong negative correlation between fluctuations in money and velocity can be seen clearly in U.S. data. In Figure 1, we illustrate this short-run behavior of money and velocity. We plot the ratio of M2 to consumption and the consumption velocity of M2 as deviations from a trend extracted using an HP-filter. These two series are strongly negatively correlated. $^{2}$ After presenting our analytical results, we examine the extent to which our model can reproduce this comovement of money and velocity in a quantitative example.

The mechanism through which our model produces a negative correlation between fluctuations in money and velocity and hence sluggish prices can be understood in two steps. First, consider how aggregate velocity is determined in this inventory-theoretic model of money demand. Households at different points in the cycle of depleting and replenishing their inventories of money in their bank accounts have different propensities to spend the

\footnotetext{
${ }^{2}$ We used the HP-filter smoothing parameter of $3^{4} \times 1600=129600$ recommended by Ravn and Uhlig (2002) for monthly data. As discussed in the Appendix, similar results are obtained using alternative measures of the short-run fluctuations in money and velocity.
} 
money that they have on hand, or, equivalently, different individual velocities of money. Households that have recently transferred funds from their brokerage account to their bank account have a large stock of money in their bank account and tend to spend this money slowly to spread their spending smoothly over the interval of time that remains before they next have the opportunity to replenish their bank account. Hence, these households have a relatively low individual velocity of money. In contrast, households that have not transferred funds from their brokerage account in the recent past and anticipate having the opportunity to make such a transfer soon tend to spend the money that they have in the bank at a relatively rapid rate, and thus have a relatively high individual velocity of money. Aggregate velocity is given by the weighted average of the individual velocities of money across all households with weights determined by the distribution of money across households.

Now consider the effects on aggregate velocity of an increase in the money supply brought about by an open market operation. In this open market operation, the government trades newly created money for interest bearing securities, and households, on the opposite side of the transaction, trade interest bearing securities held in their brokerage accounts for newly created money. If the nominal interest rate is positive, this new money is purchased only by those households that currently have the opportunity to transfer funds from their brokerage account to their bank account since these are the only households that currently have the opportunity to begin spending this money. All other households choose not to participate in the open market operation since these households would have to leave this money sitting idle in their brokerage accounts where it would be dominated in rate of return by interest bearing securities. Hence, as a result of this open market operation, the fraction of the money stock held by those households currently able to transfer resources from their brokerage account to their bank account rises. Since these households have a lower-thanaverage propensity to spend this money, aggregate velocity falls. In this way, an exogenous increase in the supply of money leads to an endogenous reduction in the aggregate velocity of money and hence, a diminished, or sluggish, response of the price level.

To this point we have modeled changes in monetary policy as exogenously specified changes in the money supply. It is now common to model changes in monetary policy not as exogenously specified changes in money but as exogenously specified changes in the short- 
term nominal interest rate. When we model monetary policy in this way, we find our second result, that expected inflation responds sluggishly to a change in the short-term nominal interest rate.

To gain intuition for the result that expected inflation responds sluggishly to a change in the short-term nominal interest rate, it is useful to consider the Fisher equation to decompose any change in the nominal interest rate into its two components - a change in the real interest rate and a change in expected inflation. For example, in a standard flexible price constant endowment cash-in-advance model, the real interest rate is always constant, so that, given the Fisher equation, any change in the nominal interest rate must always be accompanied by a matching change in expected inflation. In this sense, in this model, expected inflation must respond immediately to a change in the nominal interest rate. More generally, from the Fisher equation, if a model is to generate a sluggish response of expected inflation to a change in the nominal interest rate caused by a change in monetary policy implemented through open market operations, it must do so because those open market operations generate, in equilibrium, a change in the real interest rate that is roughly as large as the change in the nominal interest rate. In our inventory theoretic model of money demand, money injections implemented through open market operations have an effect on the real interest rate because the asset market is segmented, and it is this effect of open market operations on the real interest rate that is the source of the inflation sluggishness in our model.

Asset markets are segmented in our model in the sense that only those agents who currently have the opportunity to transfer money between their brokerage and bank accounts are at the margin in participating in open market operations and in determining asset prices. This asset market segmentation arises naturally in an inventory theoretic model of the demand for money because those agents who do not have the opportunity to transfer money between the asset and goods markets have no desire to purchase money being injected into the asset market through an open market operation because these agents have no ability to spend that money in the current period and they find that interest bearing bonds dominate money as a store of value in the asset market. ${ }^{3}$ Because only those agents who currently have the

\footnotetext{
${ }^{3}$ These agents choose not to participate in the open market operation as long as the short-term nominal interest rate remains positive. Note that financial intermediaries also choose not to hold money injected
} 
opportunity to transfer money from the asset market to the goods market are at the margin in trading money and bonds with the monetary authority, money injections implemented through open market operations have a disproportionate impact on the marginal utility of a dollar for these marginal investors that is manifest as a movement in real interest rates.

We first illustrate the mechanisms leading to a sluggish response of prices to money and inflation to interest rates in a specification of our model that is analytically tractable. In this specification of our model, households have log utility and all of the income from selling the households' endowments is deposited directly into the households' brokerage accounts. With these assumptions, the model becomes analytically tractable because households in the model choose to spend their inventories of money in their bank accounts at a rate that is independent of expectations of future prices and monetary policies. We show two main results in this analytical version of our model. First, starting from a steady-state in which the opportunity cost of holding money in a bank account is low, in response to a $1 \%$ exogenous increase in the money stock, on impact, the price level increases by only $1 / 2$ of $1 \%$ because velocity falls by $1 / 2$ of $1 \%$. We show how this result follows from the basic geometry of money holdings in an inventory theoretic model of money demand independently of the parameters governing the length of time, in calendar time, between households' opportunities to transfer cash between their brokerage and bank accounts. Second, also starting from a steady-state, in response to a one percentage point exogenous change in the nominal interest rate, on impact, the real interest rate responds by one percentage point and expected inflation does not respond at all. We show that this result follows from the asset market segmentation that is inherent in an inventory theoretic model of money demand again independently of the parameters governing the length of time, in calendar time, between households' opportunities to transfer cash between accounts.

The parameters governing the length of time between households' opportunities to transfer money between accounts are important, however, for our model's implications for the persistence of price and inflation sluggishness. These parameters also determine our model's implications for steady-state aggregate velocity — the length of calendar time between households' opportunities to transfer money determines the size of the inventory of through open market operations as long as the short-term nominal interest rate remains positive. 
money households must hold to purchase consumption. Thus, the empirical implications of our model for the sluggishness of prices and inflation are largely determined by how we define money (since that definition determines the measure of velocity and hence the magnitude of households' cash balances). In our model, defining money comes down to answering the question: What assets correspond to those that households hold in their bank accounts, and what assets do households hold and trade less frequently in their brokerage accounts?

We examine the implications of our model in a quantitative example using a broad measure of money: U.S. households' holdings of currency, demand deposits, savings deposits, and time deposits. Here we interpret households' bank accounts in our model as corresponding to U.S. households' holdings of deposits in retail commercial banks ${ }^{4}$ in the data and households' brokerage accounts in the model as corresponding to U.S. holdings of other financial assets outside of the retail commercial banking system in the data. In the data, U.S. households hold a large stock of deposits in retail banks, roughly $1 / 2$ to $2 / 3$ of the annual personal consumption expenditure. We argue for the interpretation of this broad collection of accounts in the data as corresponding to bank accounts in our model because we find in the data that U.S. households pay a large opportunity cost in terms of forgone interest to hold such accounts - on the order of 150-200 basis points. This opportunity cost is not substantially different from the opportunity cost U.S. households pay to hold a narrower definition of money like M1.

To parameterize our model to match the ratio of U.S. households' holdings of broad money relative to personal consumption expenditure, we assume households transfer funds

\footnotetext{
${ }^{4}$ In the data, retail banks correspond to a traditional conception of a commercial bank as an institution funded by consumers' checking, saving, and small time deposits. Clark et al. (2007), "The Role of Retail Banking in the U.S. Banking Industry: Risk, Return, and Industry Structure," in the Federal Reserve Bank of New York Economic Policy Review provide a useful description of retail banks in our modern financial system. As they describe, "retail banking is the cluster of products and services that banks provide to consumers and small businesses through branches, the Internet, and other channels." "Organizationally, many large banking companies have a distinct 'retail banking' business unit with its own management and financial reporting structure." "In terms of products and services, deposit taking is the core retail banking activity on the liability side. Deposit taking includes transactions deposits, such as checking and NOW accounts, and non-transaction deposits, such as savings accounts and time deposits (CD's). Many institutions cite the critical importance of deposits, especially consumer checking account deposits, in generating and maintaining a strong retail franchise. Retail deposits provide a low-cost, stable source of funds and are an important generator of fee income. Checking accounts are also viewed as pivotal because they serve as the anchor tying customers to the bank and allow cross selling opportunities."
} 
between their brokerage and bank accounts very infrequently — on the order of one every one and a half to three years. We argue that this assumption is not inconsistent with evidence summarized by Vissing-Jorgensen (2002) regarding the frequency with which U.S. households trade in high-yield assets. Our interpretation of a bank account used for transactions replenished by transfers from a high-yield managed portfolio of risky and riskless assets is the same as used in the models of Duffie and Sun (1990) and Abel, Eberly, and Panageas (2007).

We conduct two quantitative exercises with our model. In the first, we feed into the model the shocks to the stock of M2 and aggregate consumption observed in the U.S. economy in monthly data over the past 40 years and examine the model's predictions for velocity in the short-run. The model produces fluctuations in velocity that have a surprisingly high correlation of 0.60 with the fluctuations in velocity observed in the data. This result stands in sharp contrast to the implications of a standard cash-in-advance model (this model with $N=1$ ). In such a model, aggregate velocity is constant regardless of the pattern of money growth. We also find that the short-run fluctuations in velocity in our model are only $40 \%$ as large as those in the data. From the finding that the short-run fluctuations in velocity in our model are highly correlated with those observed in the data, we conclude that a substantial portion of the unconditional negative correlation of the ratio of money to consumption and velocity might reasonably be attributed to the response of velocity to exogenous movements in money. From the finding that the short-run fluctuations in velocity in our model are not as large as those in the data, however, we conclude that there may be other shocks to the demand for money which we have not modeled here.

In our second quantitative exercise, we consider the response of money, prices, and velocity to an exogenous shock to monetary policy, modeled as an exogenous, persistent shock to the short-term nominal interest rate similar to that estimated in the literature which uses vector autoregressions (VARs) to draw inferences about the effects of monetary policy. The consensus in that literature is that the impulse response of inflation to a monetary policy shock is sluggish. ${ }^{5}$ In our model we find that the impulse response of inflation is also quite

\footnotetext{
${ }^{5}$ See Cochrane (1994) and Leeper, Sims and Zha (1996) for early estimates, Christiano, Eichenbaum and Evans (1999) and Uhlig (2005) for an overview, and Christiano, Eichenbaum, and Evans (2005) for recent estimates.
} 
sluggish, as are the responses of money and the price level. All three of these responses from our model are quite similar to the estimated responses of these variables in this VAR literature. While our model is incomplete in that we have assumed for simplicity that output is exogenous, these findings suggest that our model can account for a substantial portion of the sluggish responses of nominal variables to a change in the nominal interest rate.

Our model is related to a growing literature on segmented asset markets. Grossman and Weiss (1983) and Rotemberg (1984) were the first to point out that open market operations could have effects on real interest rates and a delayed impact on the price level in inventory-theoretic models of money demand. The models they present are similar to this model when the parameter $N=2$. Those authors examine the impact of a surprise money injection in the context of otherwise deterministic models. Here we study a fully stochastic model as in Alvarez and Atkeson (1997). That model is similar to the one presented here in that agents have separate financial accounts in asset and goods markets and cannot transfer funds between these accounts in every period. In that earlier paper, however, in equilibrium, the individual velocity of money is the same for all households and is constant over time so that aggregate velocity is constant. This result follows from the assumptions in that paper that households have logarithmic utility and a constant probability of being able to transfer money between the asset market and the goods market. The asset pricing implications of our model are closely related to those obtained by Grossman and Weiss (1983), Rotemberg (1984), and Alvarez and Atkeson (1997). In particular, our model has predictions for the effects of money injections on real interest rates arising from the segmentation of the asset market related to the predictions in those papers and those in Alvarez, Atkeson, and Kehoe (2002, 2007) and Alvarez, Lucas, and Weber (2001). Alvarez, Atkeson, and Kehoe (2002, 2007) study the implications of models with segmented asset markets in which households pay a fixed cost to transfer money between bank and brokerage accounts. In that paper, they focus on equilibria in which all households spend all of the money in their bank account every period so that, again, velocity is constant.

Two closely related papers build on our framework by endogenizing segmentation (in the spirit of the original Baumol-Tobin model). Chiu (2007) studies a version of our model where households face a fixed utility cost of transferring resources between bank and brokerage 
accounts. He solves numerically for the equilibrium response of the model to a once-and-forall increase in the money supply, starting from steady state. ${ }^{6}$ He finds that the size of the initial money growth shock plays a key role in determining the response to a shock. When the money growth shock is small relative to the fixed cost, households do not pay the fixed cost and the equilibrium dynamics are the same as in an exogenous segmentation model: a money shock leads to an offsetting fall in aggregate velocity so that the price level responds sluggishly. But for a sufficiently large money injection relative to the fixed cost, all households pay the fixed cost, and so there is no offsetting fall in aggregate velocity and the price level responds one-for-one to money growth. Because of this, Chiu (2007) concludes that the results from our model are not robust to endogenous segmentation. Khan and Thomas (2007) study a version of our model where households face idiosyncratic fixed costs of transferring resources between the two accounts, ${ }^{7}$ and develop flexible numerical methods for solving the model. They show that the distribution of the idiosyncratic fixed costs plays an important role in determining the equilibrium responses of the model to a money shock. In their benchmark calibrated example, they find that these costs actually reinforce the sluggishness of prices and reinforce the persistence of liquidity effect relative to our model.

The paper proceeds as follows. We present the general model. We next present our results on the impact effects of monetary policy on prices and inflation in the analytically tractable specification of our model. We then present our quantitative exercises. In a final section, we discuss how monetary policy might affect output in a version of our model with production and a discussion of how our results compare with those on price and inflation sluggishness obtained in models with nominal rigidities.

\section{An inventory-theoretic model of money demand}

Consider a cash-in-advance economy in which the asset market and the goods market are physically separated. There is a unit mass of households each composed of a worker and

\footnotetext{
${ }^{6}$ Silva (2008) computes the equilibrium response of prices to an interest rate shock in a closely related continuous time model.

${ }^{7}$ Alvarez, Atkeson, and Kehoe (2002) use idiosyncratic fixed costs to endogenously segment asset markets, but they assume households spend all their money each period so that aggregate velocity is constant and equal to one. In Khan and Thomas (2007), as in this paper, not all households spend all their money each period and so there is a non-degenerate cross section distribution of money holdings.
} 
a shopper. Each household has access to two financial intermediaries: one that manages its portfolio of assets and another that manages its money held in a transactions account in the goods market. We refer to the household's account with the financial intermediary in the asset market as its brokerage account and its account with the financial intermediary in the goods market as its bank account. There is a government that injects money into the asset market via open market operations. Households that participate in the open market operation purchase this money with assets held in their brokerage accounts. These households must transfer this money to their bank account before they can spend it on consumption.

Time is discrete and denoted $t=0,1,2, \ldots$. The exogenous shocks in this economy are shocks to the money growth rate $\mu_{t}$ and shocks to the endowment of each household $y_{t}$. Since all households receive the same endowment, $y_{t}$ is also the aggregate endowment of goods in the economy. Let $h_{t}=\left(\mu_{t}, y_{t}\right)$ denote the realized shocks in the current period. The history of shocks is denoted $h^{t}=\left(h_{0}, h_{1}, \ldots, h_{t}\right)$. From the perspective of time zero, the probability distribution over histories $h^{t}$ has density $f_{t}\left(h^{t}\right)$.

As in a standard cash-in-advance model, each period is divided into two sub-periods. In the first sub-period, each household trades assets held in its brokerage account in the asset market. In the second sub-period, the shopper purchases consumption in the goods market using money held in the household's bank account while the worker sells the endowment in the goods market for money $P_{t}\left(h^{t}\right) y_{t}\left(h^{t}\right)$, where $P_{t}\left(h^{t}\right)$ denotes the price level in the current period. In the next period, a fraction $\gamma \in[0,1]$ of the worker's earnings is deposited in the bank account in the goods market while the remaining $1-\gamma$ of these earnings are deposited in a brokerage account in the asset market. We interpret $\gamma$ as the fraction of total income households receive regularly deposited into their transactions accounts or as currency. We refer to $\gamma$ as the paycheck parameter and to $\gamma P_{t-1}\left(h^{t-1}\right) y_{t-1}\left(h^{t-1}\right)$ as the household's paycheck. We interpret $1-\gamma$ as the fraction of total income households receive in the form of interest and dividends paid on assets held in their brokerage accounts.

Unlike a standard cash-in-advance model, households cannot transfer money between the asset market and the goods market every period. Instead, each household has the opportunity to transfer money between its brokerage account and its bank account only once every $N$ periods. In other periods, a household can trade assets in its brokerage account and use 
money in its bank account to purchase goods; it simply cannot move money between these two accounts. We refer to households that currently have the opportunity to transfer money between their accounts as active households.

Each period a fraction $1 / N$ of the households are active. We index each household by the number of periods since it was last active, here denoted by $s=0,1, \ldots, N-1$. A household of type $s<N-1$ in the current period will be type $s+1$ in the next period. A household of type $s=N-1$ in the current period will be type $s=0$ in the next period. Hence a household of type $s=0$ is active in this period, a household of type $s=1$ was active last period, and a household of type $s=N-1$ will be active next period. In period 0 , each household has an initial type $s_{0}$, with fraction $1 / N$ of the households of each type $s_{0}=0,1, \ldots, N-1$. Let $S\left(t, s_{0}\right)$ denote the type in period $t$ of a household that was initially of type $s_{0}$.

The quantity of money a household $s$ has on hand in its bank account at the beginning of goods market trade is $M_{t}\left(s, h^{t}\right)$. The shopper in this household spends some of this money on goods, $P_{t}\left(h^{t}\right) c_{t}\left(s, h^{t}\right)$, and the household carries the unspent balance in its bank account into next period, $Z_{t}\left(s, h^{t}\right)$. For an inactive household of type $s>0$, the balance in its bank account at the beginning of the period is equal to the quantity of money that it held over in its bank account last period $Z_{t-1}\left(s-1, h^{t-1}\right)$ plus its paycheck $\gamma P_{t-1}\left(h^{t-1}\right) y_{t-1}\left(h^{t-1}\right)$. Thus, the evolution of money holdings and consumption for inactive households is:

$$
\begin{aligned}
& M_{t}\left(s, h^{t}\right)=Z_{t-1}\left(s-1, h^{t-1}\right)+\gamma P_{t-1}\left(h^{t-1}\right) y_{t-1}\left(h^{t-1}\right) \\
& M_{t}\left(s, h^{t}\right) \geq P_{t}\left(h^{t}\right) c_{t}\left(s, h^{t}\right)+Z_{t}\left(s, h^{t}\right) .
\end{aligned}
$$

When a household is of type $s=0$, and hence active, it also chooses a transfer of money $P_{t} x_{t}$ from its brokerage account in the asset market into its bank account in the goods market. Hence, the money holdings and consumption of active households satisfy:

$$
\begin{aligned}
& M_{t}\left(0, h^{t}\right)=Z_{t-1}\left(N-1, h^{t-1}\right)+\gamma P_{t-1}\left(h^{t-1}\right) y_{t-1}\left(h^{t-1}\right)+P_{t}\left(h^{t}\right) x_{t}\left(h^{t}\right) \\
& M_{t}\left(0, h^{t}\right) \geq P_{t}\left(h^{t}\right) c_{t}\left(0, h^{t}\right)+Z_{t}\left(0, h^{t}\right)
\end{aligned}
$$

In addition to the bank account constraints, equations (1)-(4) above, the household also 
faces a sequence of brokerage account constraints. In each period the household can trade a complete set of one-period state contingent bonds which pay one dollar into the household's brokerage account next period if the relevant contingency is realized. Let $B_{t-1}\left(s-1, h^{t}\right)$ denote the stock of bonds held by households of type $s$ at the beginning of period $t$ following history $h^{t}$, and let $B_{t}\left(s, h^{t}, h^{\prime}\right)$ denote bonds purchased at price $q_{t}\left(h^{t}, h^{\prime}\right)$ that will pay off next period if $h^{\prime}$ is realized. Let $A_{t}\left(s, h^{t}\right) \geq 0$ denote money held by the household in its brokerage account at the end of the period. Since an inactive household of type $s>0$ cannot transfer money between its brokerage account and its bank account, this household's bond and money holdings in its brokerage account must satisfy:

$$
\begin{aligned}
& B_{t-1}\left(s-1, h^{t}\right)+A_{t-1}\left(s-1, h^{t-1}\right)+(1-\gamma) P_{t-1}\left(h^{t-1}\right) y_{t-1}\left(h^{t-1}\right)-P_{t}\left(h^{t}\right) \tau_{t}\left(h^{t}\right) \\
& \geq \int q_{t}\left(h^{t}, h^{\prime}\right) B_{t}\left(s, h^{t}, h^{\prime}\right) d h^{\prime}+A_{t}\left(s, h^{t}\right),
\end{aligned}
$$

where $\tau_{t}\left(h^{t}\right)$ denotes real lump-sum taxes. Each household's real bond holdings must remain within arbitrarily large bounds. The analogous constraint for active households is:

$$
\begin{aligned}
& B_{t-1}\left(N-1, h^{t}\right)+A_{t-1}\left(N-1, h^{t-1}\right)+(1-\gamma) P_{t-1}\left(h^{t-1}\right) y_{t-1}\left(h^{t-1}\right)-P_{t}\left(h^{t}\right) \tau_{t}\left(h^{t}\right) \\
& \geq \int q_{t}\left(h^{t}, h^{\prime}\right) B_{t}\left(0, h^{t}, h^{\prime}\right) d h^{\prime}+P_{t}\left(h^{t}\right) x_{t}\left(h^{t}\right)+A_{t}\left(0, h^{t}\right),
\end{aligned}
$$

where $P_{t}\left(h^{t}\right) x_{t}\left(h^{t}\right)$ is the active household's transfer of money from brokerage to bank account.

At the beginning of period 0, initially inactive households begin with exogenous balances $\bar{M}_{0}\left(s_{0}\right)$ in their bank accounts in the goods market. This quantity is the balance on the left side of (2) in period 0 . For initially active households, the initial balance $\bar{M}_{0}\left(0, h_{0}\right)$ in (4) is composed of an exogenous initial balance $\bar{Z}_{0}$ and a transfer $P_{0}\left(h_{0}\right) x_{0}\left(h_{0}\right)$ of their choosing. Each household also begins with exogenous balance $\bar{B}_{-1}\left(s_{0}\right)$ in its brokerage account on the left side of constraints (5) and (6). The households initially have no money corresponding to $\bar{A}_{-1}\left(s_{0}\right)$ in their brokerage accounts.

For each date and state and taking as given the prices and aggregate variables, each household of initial type $s_{0}$ chooses complete contingent plans for transfers, consumption, 
bond, and money holdings to maximize expected utility:

$$
\sum_{t=0}^{\infty} \beta^{t} \int u\left[c_{t}\left(s, h^{t}\right)\right] f_{t}\left(h^{t}\right) d h^{t}, \quad s=S\left(t, s_{0}\right)
$$

subject to the constraints (1), (2), and (5) in those periods $t$ in which $S\left(t, s_{0}\right)>0$, and constraints (3), (4), and (6) in those periods $t$ in which $S\left(t, s_{0}\right)=0$.

Let $B_{t}\left(h^{t}\right)$ be the total stock of government bonds. The government faces a sequence of budget constraints:

$$
B_{t-1}\left(h^{t}\right)=M_{t}\left(h^{t}\right)-M_{t-1}\left(h^{t-1}\right)+P_{t}\left(h^{t}\right) \tau_{t}\left(h^{t}\right)+\int q_{t}\left(h^{t}, h^{\prime}\right) B_{t}\left(h^{t}, h^{\prime}\right) d h^{\prime},
$$

together with arbitrarily large bounds on the government's real bond issuance. We denote the government's policy for money injections as $\mu_{t}\left(h^{t}\right)=M_{t}\left(h^{t}\right) / M_{t-1}\left(h^{t-1}\right)$. In period 0 , the initial stock of government debt is $\bar{B}_{-1}$ and $M_{0}\left(h_{0}\right)-\bar{M}_{-1}$ is the initial monetary injection. This budget constraint implies that the government pays off its initial debt with a combination of lump-sum taxes and money injections achieved through open market operations.

An equilibrium of this economy is a collection of prices, complete contingent plans for households, and government policy such that (i) taking as given prices and government policy, the complete contingent plans solve each household's problem, and (ii) the goods market clears $\frac{1}{N} \sum_{s=0}^{N-1} c_{t}\left(s, h^{t}\right)=y_{t}\left(h^{t}\right)$, the money market clears, $\frac{1}{N} \sum_{s=0}^{N-1}\left[M_{t}\left(s, h^{t}\right)+A_{t}\left(s, h^{t}\right)\right]=M_{t}\left(h^{t}\right)$, and the bond market clears, $\frac{1}{N} \sum_{s=0}^{N-1} B_{t}\left(s, h^{t}, h^{\prime}\right)=B_{t}\left(h^{t}, h^{\prime}\right)$ at each date and state.

To understand equilibrium money demand and asset prices, we examine the household's first order conditions. Let $\eta_{t}\left(s, h^{t}\right)$ denote Lagrange multipliers on the bank account constraints (2) and (4) of household $s$, and let $\lambda_{t}\left(s, h^{t}\right)$ denote Lagrange multipliers on the brokerage account constraints (5) and (6). Active households choose transfers $x_{t}\left(h^{t}\right)$ to equate the multipliers on the bank and brokerage accounts:

$$
\eta_{t}\left(0, h^{t}\right)=\lambda_{t}\left(0, h^{t}\right)
$$


For households of type $s$ the marginal utility of a dollar satisfies:

$$
\eta_{t}\left(s, h^{t}\right)=\beta^{t} \frac{u^{\prime}\left[c_{t}\left(s, h^{t}\right)\right]}{P_{t}\left(h^{t}\right)} f_{t}\left(h^{t}\right) .
$$

The multipliers on the bank accounts satisfy the inequalities:

$$
\eta_{t}\left(s, h^{t}\right) \geq \int \eta_{t+1}\left(s+1, h^{t}, h^{\prime}\right) d h^{\prime}
$$

which hold with equality if $Z_{t}\left(s, h^{t}\right)>0$. Combining (8)-(9) we have the consumption Euler equations that determine a household's money demand:

$$
1 \geq \int \beta \frac{u^{\prime}\left[c_{t+1}\left(s+1, h^{t}, h^{\prime}\right)\right]}{u^{\prime}\left[c_{t}\left(s, h^{t}\right)\right]} \frac{P_{t}\left(h^{t}\right)}{P_{t+1}\left(h^{t}, h^{\prime}\right)} \frac{f_{t+1}\left(h^{t}, h^{\prime}\right)}{f_{t}\left(h^{t}\right)} d h^{\prime},
$$

again, which holds with equality if $Z_{t}\left(s, h^{t}\right)>0$. The evolution of the marginal utility of a dollar in the brokerage account is determined by state contingent bond prices:

$$
q_{t}\left(h^{t}, h^{\prime}\right)=\frac{\lambda_{t+1}\left(s+1, h^{t}, h^{\prime}\right)}{\lambda_{t}\left(s, h^{t}\right)} .
$$

Under the assumption that initial conditions are such that the initial Lagrange multipliers on the brokerage account $\lambda_{0}\left(s_{0}\right)$ are the same for all households, ${ }^{8}$ equations $(7),(8)$, and (11) together imply that state contingent bond prices are then given by:

$$
q_{t}\left(h^{t}, h^{\prime}\right)=\beta \frac{u^{\prime}\left[c_{t+1}\left(0, h^{t}, h^{\prime}\right)\right]}{u^{\prime}\left[c_{t}\left(0, h^{t}\right)\right]} \frac{P_{t}\left(h^{t}\right)}{P_{t+1}\left(h^{t}, h^{\prime}\right)} \frac{f_{t+1}\left(h^{t}, h^{\prime}\right)}{f_{t}\left(h^{t}\right)} .
$$

The nominal interest rate is then found from the price of an uncontingent bond paying interest $i_{t}\left(h^{t}\right)$ in nominal terms:

$$
\frac{1}{1+i_{t}\left(h^{t}\right)}=\int q_{t}\left(h^{t}, h^{\prime}\right) d h^{\prime}=\int \beta \frac{u^{\prime}\left[c_{t+1}\left(0, h^{t}, h^{\prime}\right)\right]}{u^{\prime}\left[c_{t}\left(0, h^{t}\right)\right]} \frac{P_{t}\left(h^{t}\right)}{P_{t+1}\left(h^{t}, h^{\prime}\right)} \frac{f_{t+1}\left(h^{t}, h^{\prime}\right)}{f_{t}\left(h^{t}\right)} d h^{\prime} .
$$

In what follows, we will characterize equilibrium in an analytically tractable specifi-

\footnotetext{
${ }^{8}$ This can be ensured by an appropriate choice of initial bond holdings $\bar{B}_{0}\left(s_{0}\right)$ or with the assumption that households trade securities contingent on their initial type $s_{0}$ in an initial asset market before they learn this type.
} 
cation of our model using methods similar to those used in a Lucas-tree economy (see Lucas 1978). That is, we will find the allocations of money and consumption across households implied by market clearing and then solve for asset prices in terms of marginal utilities using the first order conditions linking bond prices to ratios of marginal utilities above. To gain intuition as to how these prices lead households to choose to purchase more or less money in an open market operation as required in equilibrium to match the central bank's policy for money injections, we find it useful to recast these first order conditions in terms of the date zero asset prices implied by our state contingent bond prices. Specifically, let $Q_{t}\left(h^{t}\right)$ denote the price in period 0 of one dollar delivered in the asset market in period $t$ following history $h^{t}$. These prices satisfy the recursion $Q_{t}\left(h^{t}\right)=Q_{t-1}\left(h^{t-1}\right) q_{t-1}\left(h^{t-1}, h_{t}\right)$ for $t \geq 1$.

From (11) and the recursion for date zero prices we then have that for all households:

$$
Q_{t}\left(h^{t}\right)=\lambda_{t}\left(s, h^{t}\right)
$$

Again, using the assumption that initial conditions are such that the initial Lagrange multipliers on the brokerage account $\lambda_{0}\left(s_{0}\right)$ are the same for all households, from (7)-(8), we have that asset prices are determined by the marginal utility for active households:

$$
Q_{t}\left(h^{t}\right)=\beta^{t} \frac{u^{\prime}\left[c_{t}\left(0, h^{t}\right)\right]}{P_{t}\left(h^{t}\right)} f_{t}\left(h^{t}\right)
$$

A large money injection at $t$ and $h^{t}$ is associated with a low date zero price $Q_{t}\left(h^{t}\right)$ and large purchases of money by those households that are currently active (obtained by selling bonds). These active households then transfer this money immediately to their bank accounts and begin spending it, so the low date zero price $Q_{t}\left(h^{t}\right)$ is associated with high consumption $c_{t}\left(0, h^{t}\right)$ for households that happen to be active at this date. Likewise, a small money injection at $t$ and $h^{t}$ is associated with a high date zero price $Q_{t}\left(h^{t}\right)$ and small purchases of money and low consumption by those households that are currently active.

The mechanism through which money injections in this model have an impact on "real" asset prices is also most easily understood in terms of these date zero asset prices. We can define a real asset price as the price at date zero of a claim to sufficient cash to purchase one unit of consumption at date $t$ following history $h^{t}$. This price is given by $Q_{t}\left(h^{t}\right) P_{t}\left(h^{t}\right)$. 
Note from (15) that this asset price is equal to the marginal utility of consumption of the households that are active at date $t$. In a standard cash-in-advance model, all households are active at each date and consumption is exogenous so this real asset price is invariant to the specification of monetary policy. As we show below, in our model, money injections redistribute cash holding across households and thus impact the consumption of the subset of agents who are active at a given date. Corresponding to this redistributive effect, in our model, money injections thus also impact real asset prices in equilibrium.

To this point, we have made explicit reference to uncertainty in the notation so as to give a clear characterization of state contingent asset prices. For the remainder of the paper

we suppress reference to histories $h^{t}$ to conserve notation. The inequalities governing money demand can therefore be written:

$$
1 \geq E_{t}\left\{\beta \frac{u^{\prime}\left[c_{t+1}(s+1)\right]}{u^{\prime}\left[c_{t}(s)\right]} \frac{P_{t}}{P_{t+1}}\right\}
$$

with strict equality if $Z_{t}(s)>0$, while the price for bonds can be written:

$$
\frac{1}{1+i_{t}}=E_{t}\left\{\beta \frac{u^{\prime}\left[c_{t+1}(0)\right]}{u^{\prime}\left[c_{t}(0)\right]} \frac{P_{t}}{P_{t+1}}\right\} .
$$

\section{How the model works}

In this section, we solve our model for a special case that is analytically tractable to demonstrate how the model works. In this special case, agents have utility $u(c)=\log (c)$ and the paycheck parameter is $\gamma=0$. Given these assumptions, households of type $s$ spend a constant fraction $v(s)$ of their current money holdings and carry the remaining fraction $1-v(s)$ into the next period, irrespective of the future path of money and prices. As a result of the fact that agents choose this simple pattern of expenditure we can, in this special case, solve analytically for the dynamic, stochastic equilibrium of our model.

We use this analytical example to first show how the price level responds sluggishly to an exogenous change in money growth and then show how inflation responds sluggishly to an exogenous change in the nominal interest rate. In the next section, we explore the quantitative implications of our model for illustrative examples in which household expenditure does vary 
with the future path of money and prices because agents have preferences other than log utility and/or the paycheck parameter is positive.

In presenting this version of the model, we allow the length of a time period to be an arbitrary $\Delta>0$ units of calendar time (measured in fractions of a year). We continue to use $t$ to count time periods so after $t$ periods $t \Delta$ units of calendar time have passed. We refer to flow variables such as consumption at annual rates so that $c_{t} \Delta$ is consumption in period $t$. Likewise, the discount factor for the flow utility is $\beta^{\Delta}$, where $\beta$ reflects discounting in preferences at an annual rate. We let $T>0$ denote the calendar length of time between activity for households so that $N=T / \Delta$ is the number of periods that elapse between activity. We first derive results for an arbitrary length of a period $\Delta$ and then focus attention on particularly simple formulas that obtain when we let $\Delta \rightarrow 0$ for fixed $T$ (so that $N$ approaches infinity). We focus on the case of an arbitrarily small time period to show that the time period in our model does not have any economic significance and because this helps simplify the resulting formulas. For expositional purposes, we leave all the algebraic details to the Appendix.

In our analysis here, we assume that, in equilibrium, nominal interest rates are positive so that households choose not to hold money in their brokerage accounts where money is dominated in rate of return by bonds and that the opportunity cost of holding money in a bank account is high so that those households who are about to transfer money between their brokerage and bank accounts do not hold money in their bank accounts. These conditions are analogous to the cash-in-advance constraint binding in a standard cash-in-advance model (this model with $N=1$ ). After solving the model under these assumptions, one can use equations (16) and (17) to check the first order conditions governing these two assumptions regarding money holdings.

\section{A. Money and velocity}

In our model, households periodically withdraw money from the asset market and then spend that money slowly in the goods market to ensure it lasts until they have another opportunity to withdraw money from the asset market. As a result, households' equilibrium paths for money holdings have the familiar saw-toothed shape characteristic of inventory- 
theoretic models of money demand. Here we discuss how this saw-toothed pattern of money holdings shapes our model's implications for the dynamics of money, velocity, and prices.

Given our assumption that households have utility $u(c)=\log (c)$ and the paycheck parameter is $\gamma=0$, households' money holdings and nominal spending at period $t$ for a period of length $\Delta$ are given by:

$$
M_{t+1}(s+1)=(1-v(s) \Delta) M_{t}(s) \text { and } P_{t} c_{t}(s) \Delta=v(s) \Delta M_{t}(s)
$$

with

$$
v(s) \equiv \frac{1}{\Delta} \frac{1-\beta^{\Delta}}{1-\beta^{\Delta(N-s)}} .
$$

We refer to the fraction $v(s)$ as the individual velocity of money at an annual rate and to $v(s) \Delta$ as individual velocity in period $t$. Note that, in this special case of our model, these individual velocities of money are constant over time regardless of expectations of the future path of money and prices. Observe that these individual velocities $v(s) \Delta$ converge to $1 /(N-s)$ as $\beta$ approaches one. In this limiting case, the nominal expenditure of each household is constant over time as it is assumed in the original Baumol-Tobin framework.

Given that individual velocities $v(s) \Delta$ are constant in this specification of our model, aggregate velocity at any date or state is simply a function of the distribution of money across these households with different individual velocities. If the nominal interest rate is positive, so that households do not hold any money in the asset market, money market clearing implies:

$$
M_{t}=\frac{1}{N} \sum_{s=0}^{N-1} M_{t}(s) .
$$

Accordingly, we interpret $\left\{M_{t}(s) / M_{t}\right\}_{s=0}^{N-1}$ as the distribution of money holdings across households. Goods market clearing then implies the aggregate velocity of money is a weighted average of the individual velocities of money where the weights are given by the distribution 
of money holdings across households:

$$
v_{t} \equiv \frac{P_{t} y_{t}}{M_{t}}=\frac{1}{N} \sum_{s=0}^{N-1} \frac{P_{t} c_{t}(s)}{M_{t}}=\frac{1}{N} \sum_{s=0}^{N-1} v(s)\left(\frac{M_{t}(s)}{M_{t}}\right)
$$

where $v_{t}$ is aggregate velocity at an annual rate.

In a steady-state with constant money growth, the distribution of money holdings across households of different types is constant. Hence aggregate velocity is also constant and the steady-state inflation rate is equal to the money growth rate. Therefore our model predicts that in the long-run, along a steady-state growth path, the price level and the money supply grow together while the aggregate velocity of money stays constant.

Out of steady-state, however, as a result of the fact that the individual velocities of money $v(s) \Delta$ vary across households with different values of $s$, fluctuations in aggregate money growth cause fluctuations in the distribution of money across households, and this in turn causes fluctuations in aggregate velocity. More specifically, the dynamics of prices, velocity, and money are determined by two factors: first, the differences in individual velocities $v(s) \Delta$ across households of different types and second, the effect of a money injection on the distribution of money holdings across households. How these factors affect fluctuations in aggregate velocity can be understood intuitively as follows.

First, consider the differences in individual velocities $v(s) \Delta$. These measures of individual velocity equal the flow of consumption obtained by that household relative to its money holdings at the beginning of the period. From (19), we immediately see that $v(s) \Delta$ is increasing in $s$. A household of type $s$ close to zero holds a large stock of money relative to its consumption while a household of type $s$ close to $N-1$ holds only a small stock of money relative to its consumption.

Next consider how a money injection affects the distribution of money across households. From (18), the evolution of the distribution of money for households of type $s=$ $1, \ldots, N-1$ is given by:

$$
\frac{M_{t}(s)}{M_{t}}=(1-v(s-1) \Delta) \frac{M_{t-1}(s-1)}{M_{t-1}} \frac{1}{\mu_{t}^{\Delta}},
$$


using $\mu_{t}=\left(M_{t} / M_{t-1}\right)^{1 / \Delta}$ to denote money growth at an annual rate. Since the distribution of money must sum to one, the money holdings of active households are:

$$
\frac{1}{N} \frac{M_{t}(0)}{M_{t}}=1-\frac{1}{N} \sum_{s=1}^{N-1}(1-v(s-1) \Delta) \frac{M_{t-1}(s-1)}{M_{t-1}} \frac{1}{\mu_{t}^{\Delta}}
$$

Given an initial distribution of money holdings across households and a process for money growth $\mu_{t}$, equations (22) and (23) completely characterize the equilibrium dynamics of the distribution of money holdings across households and hence the equilibrium dynamics of aggregate velocity and the price level.

This law of motion for the distribution of money has two key implications. First, in response to an increase in the money supply, aggregate velocity falls and thus the price level responds less than one-for-one with the money supply. Hence, prices in this model are sluggish in that they move less than would be predicted by the simplest quantity theory. Specifically, the proportional response of prices on impact is roughly half as large as the proportional change in the supply of money. Second, there is a persistently sluggish response of prices to changes in the quantity of money, and the extent of persistence is increasing in the calendar length of time between periods of activity.

To see these implications, consider first the impact effect of a money injection on velocity. By redistributing money towards the active households, an increase in the supply of money tilts the distribution of money holdings towards agents with low individual velocities and away from agents with high individual velocities, lowering aggregate velocity. To see this result more formally, we proceed in two steps. In the first step, we derive the elasticity of velocity with respect to money growth for an arbitrary period length and show that the elasticity is negative — so that on impact velocity declines when money growth increases. In the second step, we consider the case of an arbitrarily small period length.

To derive the elasticity of velocity with respect to money growth in period $t$ analytically, from equations (21), (22), and (23) observe:

$$
\frac{\partial\left(v_{t} \mu_{t}^{\Delta}\right)}{\partial \mu_{t}^{\Delta}}=v(0)
$$


Hence the elasticity of velocity with respect to money growth in period $t$ is given by:

$$
\frac{\partial \log \left(v_{t}\right)}{\partial \log \left(\mu_{t}^{\Delta}\right)}=\left[\frac{\partial\left(v_{t} \mu_{t}^{\Delta}\right)}{\partial \mu_{t}^{\Delta}}-v_{t}\right] \frac{1}{v_{t}}=\frac{v(0)-v_{t}}{v_{t}} .
$$

Since the individual velocity of active households is less than aggregate velocity $\left(v(0)<v_{t}\right)$, aggregate velocity declines when money growth increases. Given the exchange equation $M_{t} v_{t}=P_{t} y_{t}$, we see that the price level does not respond on impact one-for-one with an increase in the money supply since that increase in the money supply leads to an endogenous decrease in aggregate velocity.

To quantify this elasticity, we evaluate velocity at steady-state $v_{t}=\bar{v}$. To simplify the formulas, we suppose the steady-state money growth rate is $\bar{\mu}=1$ and the time discount factor $\beta \rightarrow 1$ so that the steady-state real return to holding money, $\beta / \bar{\mu}$, also goes to one. In this limiting case, the expenditure of each household is constant over time as in the original Baumol-Tobin framework.

In this limit, individual velocity of active households per period $v(0) \Delta=\Delta / T$ and steady-state aggregate velocity per period is $\bar{v} \Delta=2 /(T / \Delta+1)$ so that, under these assumptions, the elasticity of aggregate velocity with respect to period money growth is:

$$
\frac{\partial \log (v)}{\partial \log \left(\mu^{\Delta}\right)}=-\frac{1}{2} \frac{T / \Delta-1}{T / \Delta}, \quad \text { and } \quad \frac{\partial \log (\pi)}{\partial \log \left(\mu^{\Delta}\right)}=\frac{1}{2} \frac{T / \Delta+1}{T / \Delta}
$$

where these derivatives are evaluated at steady-state and where $\pi$ denotes the inflation rate.

We can see here that if $T=\Delta$ so that $N=1$, as in a standard cash-in-advance model, inflation responds one-for-one with the shock to money growth and velocity is constant. In contrast, if for fixed $T$ we take $\Delta \rightarrow 0$, then inflation responds only $1 / 2$ as much as money growth. This result follows from the geometry of money holdings implied by an inventorytheoretic model - a household that has just replenished its bank account will hold roughly twice as much money as an average household and hence have roughly half the velocity of the average household.

Note that here, as we consider the limit as the time period $\Delta$ shrinks to zero, we also shrink the magnitude of the money injection to zero. To be able to properly interpret the impact effect, we now specify our model with a small yet finite value of $\Delta$ and consider the 
effect of a sequence of money injections carried out gradually, one per model period, that cumulate over time to a sizable injection. To be specific, we set $\Delta$ to correspond to a day, and calculate the effects of a total increase in the money supply of $1 \%$ accomplished via a sequence of equally sized money injections, one per model period, over the course of one month, i.e., a money injection that increases the money supply by $1 / 30$ th of $1 \%$ for 30 days, a shock of $0.0333 \%$ each day for 30 days. Our analytical results characterize the response of velocity and prices to the money injection on the first day, since we start the model off from a steady-state. After the first day, however, the distribution of money holdings across households is no longer in steady-state and we must track the impact of the remaining money injections numerically.

Figure 2 illustrates the dynamics of money, velocity, and prices following this shock. In response to this money injection, aggregate velocity falls and the price level responds less than one-for-one with the change in the money supply. As we showed analytically, the elasticity of velocity with respect to money growth near steady-state is approximately $-1 / 2$. The impact effect of the first day's money injection on velocity is $-0.0166 \%$, very close to the analytical value of $0.5 \times-0.0333 \%$ to be expected. Tracking the effects of the remaining 29 money injections gives the cumulative effect of this sequence of money injections at time $t=30$ days on velocity of $-0.48 \%$, approximately $-1 / 2$ of the cumulative shock of $1.00 \%$ that was introduced over those 30 days. In the figure, we trace out the dynamics of money and prices for a total of 300 days (or 10 months). Over time, aggregate velocity and prices rise, even overshooting their steady-state levels, and then gradually converge to steady-state with dampened oscillations.

The results displayed in Figure 2 regarding the impact of a 1\% increase in the money stock carried out over one month are very similar to the results that we obtain when we simply set the length of the model period $\Delta$ to correspond to one month and calculate the effect of a $1 \%$ increase in the money supply accomplished in a single model period (the corresponding figure is available upon request).

The dynamics of velocity following a shock can be understood as follows. Since the money growth rate is high for only one month, from (22) we see that the households who were active at the time of the money injection carry an abnormally large stock of money until 
they next have the opportunity to transfer funds from their brokerage account. As shown in (19), their individual velocities rise each period until this next visit occurs. Thus, aggregate velocity remains below its steady-state level for a time initially as these agents have a low individual velocity and then rises past its steady-state level as the individual velocity for these agents rises. After $N$ months these agents have spent all of their money and they visit the asset market again. If this were the only effect, we would expect aggregate velocity to return to its steady-state value in $N / 2$ months. However, we show in the Appendix that aggregate velocity remains below its steady-state value for approximately $N \log (2)$ months, well over $N / 2$ months (since $\log (2) \approx 0.69$ ). In this sense, there is persistence in the sluggish response of prices to changes in the quantity of money and this persistence is increasing in $N$. The periodic structure of the model introduces a sequence of dampened oscillations in velocity as the changes in the distribution of money holdings work their way through the system. After the first $N$ months, however, these effects are quite small.

\section{B. Interest rates and inflation}

Until now, we have taken as given the path of money growth and examined our model's implications for the responses of velocity and the price level to a shock to money growth. An alternative approach is to discuss monetary policy in terms of interest rates and solve endogenously for the responses of money growth, velocity, and inflation consistent with a shock to nominal interest rates. We turn now to such an analysis. Here we show our main result that, on impact, inflation responds sluggishly to a shock to interest rates.

We demonstrate analytically that the response of inflation to a change in the nominal interest rate is sluggish in our model when $N$ is large, again under the assumptions that $u(c)=\log (c)$ and $\gamma=0$ so that individual velocities $v(s)$ are time-invariant. We solve for the responses of money growth, velocity, and inflation to a change in the nominal interest rate in a deterministic setting. Specifically, we assume the nominal interest rate, inflation, money growth, and the distribution of money holdings across households (and hence velocity) are all initially at steady-state values corresponding to a constant interest rate $\bar{\imath}$. We fix at $t=0$ an increase in the nominal rate above steady-state, $i_{0}>\bar{\imath}$. We solve for the response of inflation, money growth, and velocity consistent with this change in the nominal interest rate. 
To solve for these responses, we use the pricing formula for nominal bonds (17). In a deterministic setting, this formula can be rewritten as a Fisher equation relating nominal interest rates, real interest rates, and inflation between the current period and the next:

$$
\hat{\imath}_{t}=\hat{r}_{t}+\hat{\pi}_{t+1}
$$

where a "hat" denotes log deviation from steady-state and where we repeatedly use approximations of the form $\log \left(1+i_{t}\right) \approx i_{t}$.

We use this Fisher equation to find a path for money growth such that the implied paths for inflation and the real interest rate are consistent with the exogenously specified path for the nominal interest rate. Recall that, in our model, changes in the path of money growth have an impact on velocity, inflation, and real interest rates, with the magnitude of these changes depending on $N$.

As a benchmark, consider first the responses of money growth, velocity, and inflation when $N=1$ (so that our model is a standard constant-velocity cash-in-advance model). With $N=1$, all households are active, velocity is constant, and the consumption of active households is also constant at $c_{t}(0)=y$. As a result, in this case, inflation is equal to money growth $\left(\hat{\pi}_{t+1}=\hat{\mu}_{t+1}\right)$ and the real interest rate is constant $\left(\hat{r}_{t}=0\right)$. With these results, we see that any path of money growth that is consistent with our exogenously specified path of nominal interest rates must have money growth $\hat{\mu}_{1}$ and inflation $\hat{\pi}_{1}$ responding one-for-one to the change in the nominal interest rate in period 0 . That is, $\hat{\mu}_{1}=\hat{\imath}_{0}$. Clearly, in this case, the response of inflation from period $t=0$ to $t=1$ anticipated in period $t=0$ in response to the change in the nominal interest rate $\hat{\imath}_{0}$ is not at all sluggish.

Our solution of the model in this benchmark case with $N=1$ is not yet complete as we have not solved for the equilibrium responses of money growth $\hat{\mu}_{0}$ and inflation $\hat{\pi}_{0}$ on impact, at date $t=0$. It is well known that in this textbook cash-in-advance model $(N=1)$, this initial money growth rate and inflation rate are not determinate under an exogenous interest rate rule. We resolve the indeterminacy by choosing the particular path of money growth $\hat{\mu}_{0}$ so that, on impact, inflation from the last period to the current period does not respond to the change in the nominal interest rate in the current period (i.e., so that $\hat{\pi}_{0}=0$ ). In the 
model with $N=1$, this is achieved by setting $\hat{\mu}_{0}=0$. This resolution of the indeterminacy is equivalent to assuming that the price level in period $t=0$ does not respond to the change in the nominal interest rate and hence is consistent with the schemes used to identify shocks to monetary policy discussed in Christiano, Eichenbaum, and Evans (1999). Note that this resolution of the indeterminacy fixes the responses of money growth and inflation at date $t=0$ by assumption. What is of interest are the equilibrium values of money growth and inflation at date $t=1, \hat{\mu}_{1}$ and $\hat{\pi}_{1}$.

We now turn to the case of a general $N>1$. At the end of this section, we show that this indeterminacy of the initial money growth rate $\hat{\mu}_{0}$ given the exogenous path of the nominal interest rate extends to our setting with $N>1$. In particular, we show that, as in the case with $N=1$, there is a continuum of paths of money growth consistent with a given path of nominal interest rates. As in the case with $N=1$, with $N>1$, this continuum has only one dimension, that is, these paths can be indexed by their initial money growth rates $\hat{\mu}_{0}$ despite the fact that this model has a non-degenerate distribution of money holdings across households as a state variable that is absent from the model with $N=1$. Here, we again resolve this indeterminacy by examining the path of money growth consistent with $\hat{\pi}_{0}=0$. Given our assumption of $\log$ utility and $\gamma=0$ so that individual velocities are constant over time, this path of money growth has initial money growth at its steady-state level $\hat{\mu}_{0}=0$.

Given this result that $\hat{\mu}_{0}=0$ under our resolution of the indeterminacy under an interest rate rule, we solve for the equilibrium responses of money growth $\hat{\mu}_{1}$, velocity $\hat{v}_{1}$, and inflation $\hat{\pi}_{1}$ to the change in the nominal interest rate $\hat{\imath}_{0}$ in period $t=0$ by finding the value of money growth $\hat{\mu}_{1}$ such that the equilibrium responses of the real interest rate $\hat{r}_{0}$ and inflation $\hat{\pi}_{1}$ are consistent with the assumed movement in the nominal interest rate. We solve for each of these responses in turn.

Consider first the response of the real interest rate $\hat{r}_{0}$ to a change in money growth $\hat{\mu}_{1}$. This real interest rate is determined by the growth of the consumption of active households according to $\hat{r}_{0}=\hat{c}_{1}(0)-\hat{c}_{0}(0)$. Given that the individual velocity for active households $v(0)$ is constant over time, the consumption of active households is given by $c_{t}(0)=v(0) m_{t}(0) M_{t} / P_{t}$, where $m_{t}(0)=M_{t}(0) / M_{t}$ is the share of the money supply held by active households. The 
real interest rate can therefore be written:

$$
\hat{r}_{0}=\hat{m}_{1}(0)-\hat{m}_{0}(0)+\hat{\mu}_{1}-\hat{\pi}_{1}
$$

Given that initial inflation and money growth are at their steady-state values, and given our assumed initial conditions, the distribution of money holdings across households at date $t=0$ is equal to its steady-state value, and hence the share of the money supply held by active households $m_{t}(0)$ and velocity $v_{t}$ are also equal to their steady-state values. Thus, we have $\hat{m}_{0}(0)=0$ and:

$$
\hat{r}_{0}=\left[\frac{\partial \log (m(0))}{\partial \log (\mu)}+1-\frac{\partial \log (\pi)}{\partial \log (\mu)}\right] \hat{\mu}_{1},
$$

where $\partial \log (m(0)) / \partial \log (\mu)$ and $\partial \log (\pi) / \partial \log (\mu)$ are the elasticities of the share of money held by active households and of inflation with respect to money growth, both evaluated at the steady-state. From (28), these results then imply that the money growth required in period 1 to implement the nominal interest rate $\hat{\imath}_{0}$ in period 0 is given by:

$$
\hat{\mu}_{1}=\left[\frac{1}{1+\frac{\partial \log (m(0))}{\partial \log (\mu)}}\right] \hat{\imath}_{0}
$$

Thus, the real interest rate and inflation rate are given by:

$$
\hat{r}_{0}=\left[1-\frac{\frac{\partial \log (\pi)}{\partial \log (\mu)}}{1+\frac{\partial \log (m(0))}{\partial \log (\mu)}}\right] \hat{\imath}_{0}, \quad \text { and } \quad \hat{\pi}_{1}=\left[\frac{\frac{\partial \log (\pi)}{\partial \log (\mu)}}{1+\frac{\partial \log (m(0))}{\partial \log (\mu)}}\right] \hat{\imath}_{0}
$$

To discuss these formulas, we return to the setting where periods are measured in $\Delta$ units of calendar time with $T>0$ denoting the calendar length of time between activity so that $N=T / \Delta$ is the number of periods that elapse between activity. As we can see from these formulas, the difference between our model and the standard model with $T=\Delta$ comes through the terms $\partial \log (m(0)) / \partial \log (\mu)$ and $\partial \log (\pi) / \partial \log (\mu)$ reflecting the elasticities of the share of money held by active households and of inflation with respect to a money injection. In the standard model with $T=\Delta$ (i.e., $N=1$ ), a money injection has no effect in terms of redistributing money holdings across households so that this elasticity is zero and 
the elasticity of inflation with respect to money growth is one. Thus, as we have seen, in this case, money growth and inflation respond one-for-one with the nominal interest rate and the real interest rate remains constant. In contrast, with $T>\Delta$ (i.e., $N>1$ ), the elasticity of the share of money holdings of active households with respect to money growth is positive and grows large as $\Delta \rightarrow 0$. Specifically, we show in the Appendix that, taking the limit as $\beta / \bar{\mu} \rightarrow 1$, the elasticity of the money share of active agents is approximately:

$$
\frac{\partial \log (m(0))}{\partial \log (\mu)}=\frac{T / \Delta-1}{2}
$$

And, as we showed above, the elasticity of inflation is $\partial \log (\pi) / \partial \log (\mu)=(T / \Delta+1) / 2(T / \Delta)$, which is less than one for $T>\Delta$ and falls towards $1 / 2$ as $\Delta \rightarrow 0$. Plugging in these expressions for the elasticities gives:

$$
\hat{\mu}_{1}=\frac{2}{T / \Delta+1} \hat{\imath}_{0}, \quad \text { and } \quad \hat{\pi}_{1}=\frac{1}{T / \Delta} \hat{\imath}_{0}
$$

and that the real interest rate is:

$$
\hat{r}_{0}=\frac{T / \Delta-1}{T / \Delta} \hat{\imath}_{0}
$$

The size of the response of real interest rates to a change in the nominal interest rate on impact is measured by $(T / \Delta-1) /(T / \Delta)$, which is decreasing in $\Delta$. For small $\Delta$, a given increase in the nominal interest rate gives rise to a nearly one-for-one increase in the real rate and almost no increase in expected inflation. The small response of inflation to a change in interest rates comes from segmented asset markets: only the fraction $\Delta / T$ (i.e., $1 / N$ ) of households that are active receive the entire increase in the money supply, and so a given money injection has a disproportionately large impact on the marginal utility of a dollar for these households. Therefore, for small $\Delta$ a given change in nominal interest rates is obtained with a small change in money growth because that small change in the money supply has a large impact on real interest rates. Inflation is sluggish when $\Delta$ is small because this small change in money growth leads only to a small change in inflation.

In our model, taking $\Delta \rightarrow 0$ has two effects that together contribute to the sluggish 
response of inflation — reducing $\Delta$ increases the elasticity of the share of money held by active households and lowers the elasticity of inflation with respect to a change in money growth. The more important of these two effects is the first one. To see this, consider a constant velocity model in which agents are permanently divided into a fraction $\lambda$ who are always active and a remaining fraction $1-\lambda$ who are never active, as in Alvarez, Lucas, and Weber (2001). Then, using the same resolution of the indeterminate price level, the relationship between real and nominal rates on impact is still given by (31) above. Since aggregate velocity is constant in this alternative model, $\partial \log (\pi) / \partial \log (\mu)=1$. It can also be shown that in this case the elasticity of the share of money held by the permanently active agents to money growth is $\partial \log (m(0)) / \partial \log (\mu)=(1-\lambda) / \lambda$. Therefore the response of the real rate is:

$$
\hat{r}_{0}=(1-\lambda) \hat{\imath}_{0}
$$

So if the fraction of agents who are always active in this alternative model is $\lambda=\Delta / T$ (i.e., $\lambda=1 / N)$, then the alternative model with constant velocity gives the same response of inflation on impact to a change in the nominal interest rate as our model with variable velocity. In this sense, our result that the response of inflation to a change in interest rates is sluggish is driven by mainly by asset market segmentation and not variable velocity.

For the remainder of this paper, for computational simplicity, we fix the period length to $\Delta=1$ month so that $N=T$ is the calendar length of time between activity in months.

We now present the indeterminacy result that holds in our model.

Proposition 1. Let $\left\{i_{t}^{*}\right\}_{t=0}^{\infty}$ be a given sequence of nominal interest rates and $M_{-1}^{*}(s)$ be the initial distribution of money holdings across households. Let $\left\{M_{t}^{*}, M_{t}^{*}(s), c_{t}^{*}(s), P_{t}^{*}\right\}_{t=0}^{\infty}$ be an equilibrium corresponding to this sequence of interest rates and these initial conditions. Then, for each $M_{0}$ in an open neighborhood of $M_{0}^{*}$, there exists a unique equilibrium $\left\{M_{t}, M_{t}(s), c_{t}(s), P_{t}\right\}_{t=0}^{\infty}$ consistent with the same path of interest rates $\left\{i_{t}^{*}\right\}_{t=0}^{\infty}$ and initial distribution of money holdings $M_{-1}^{*}(s)$. In this alternative equilibrium, for $t \geq N$, the distri- 
bution of consumption, money growth, and inflation are unchanged in that

$$
c_{t}(s)=c_{t}^{*}(s), \frac{M_{t+1}}{M_{t}}=\frac{M_{t+1}^{*}}{M_{t}^{*}} \text { and } \frac{P_{t+1}}{P_{t}}=\frac{P_{t+1}^{*}}{P_{t}^{*}} .
$$

For periods $t=0, \ldots, N-1$, however, the distribution of consumption, money growth, and inflation all depend on the value of $M_{0}$.

Proof. See the Appendix.

This indeterminacy result reduces to the standard indeterminacy result when $N=1$. (See, for example, Woodford 2003b, chapter 2, for an extended discussion.) And since for each $M_{0}$ there is a unique alternative equilibrium, even for $N>1$ the indeterminacy is onedimensional, as in the standard model. However, for $N>1$, this indeterminacy result differs from the standard result in that the distribution of consumption across agents and the path of money growth and inflation differ across these equilibria for the first $N$ periods. Hence, for $N>1$, this indeterminacy has implications for real quantities and the real interest rate despite the fact that prices are fully flexible.

\section{Quantitative exercises}

The set-up used in the previous section, with $u(c)=\log (c)$ and $\gamma=0$, simplifies calculations since individual velocities $v(s)$ are time invariant. In the case where $\gamma>0$ or for general $u(c)$ the dynamics are more complex, since households' expenditure decisions will be forward-looking and consequently individual velocities will be time-varying. Below, we examine the quantitative implications of our model for the persistence of the sluggish response of prices to money and inflation to interest rates under alternative parameterizations of our model numerically. We characterize the responses of prices and inflation numerically with values of the parameters $N$ and $\gamma$ chosen so that our model reproduces both the average level of velocity for a broad monetary aggregate held by U.S. households and the fraction of personal income that is received as wage and salary disbursements. ${ }^{9}$ We then conduct two exercises with the model to illustrate its quantitative implications.

\footnotetext{
${ }^{9}$ The other parameters we need to assign are standard. We set the length of the time period to be a month, the time discount factor $\beta=0.99^{1 / 12}$, i.e., a $1 \%$ annual rate, and the steady-state money growth to be $\bar{\mu}=1.01^{1 / 12}$ also a $1 \%$ annual rate, which is consistent with a $2 \%$ annual opportunity cost of money, as discussed below. We set the coefficient of relative risk aversion to one, i.e., log utility.
} 
In the first exercise, we examine our model's quantitative implications for the response of velocity to changes in money growth. In this experiment, we feed into the model the sequences of money growth and aggregate consumption shocks observed in U.S. data and compare the model's implications for the short-run fluctuations in velocity with those observed in the data. We find that velocity in the model is highly correlated with velocity in the data. The magnitude of the fluctuations in the model, however, are significantly smaller than the magnitude of those observed in the data.

In the second exercise, we examine the responses of money, prices, and velocity in the model to a monetary policy shock represented as a persistent movement in the nominal interest rate similar to those estimated as the response of the Federal Funds rate to a monetary policy shock in the VAR literature. Here we find that the corresponding impulse responses of money and prices implied by our model are similar to those estimated in the VAR literature. In particular, inflation in the model responds quite sluggishly to the change in interest rates.

\section{A. Choosing $N$ and $\gamma$}

In specifying our model, we have assumed that households hold their financial assets in two separate accounts, which we term a bank account and a brokerage account, respectively. The bank account is used to purchase consumption and offers a low rate of return on the assets deposited there while the brokerage account can be used to hold a wide array of high yielding financial assets. Transfers between the two accounts are assumed to be infrequent.

To map the parameters of the model to observables in the data, we must interpret the theoretical objects in the model in terms of actual financial institutions in the data. Our preferred interpretation is to map the bank accounts in the model to what is called "retail banking" in the data while the brokerage accounts in the model correspond to the array of actual brokerage accounts, mutual fund shares, pension funds, life insurance reserves, and equity in non-corporate businesses within which households hold claims on financial assets in a form that is not readily accessible for consumption purposes. We choose this interpretation of bank and brokerage accounts in our model based on the observation, documented in the Appendix, that U.S. households pay a substantial cost (on the order of 2 percentage points)

in terms of foregone interest to hold assets in retail banks relative to short-term Treasury 
securities. The evidence that we present indicates that there is no substantial difference in the opportunity cost of demand deposits (in M1) and the components of M2 (savings and time deposits) that we consider as part of our monetary aggregate.

Our interpretation of bank and brokerage accounts differs from the traditional interpretation of Baumol-Tobin models, where withdrawals are made from a safe interest-bearing asset into cash. Instead, we interpret the bank accounts as a broader monetary aggregate, and the account from which these transfers are made as one with high-yield managed portfolios of risky and riskless assets. Our interpretation is the similar to those in the models of Duffie and Sun (1990) and Abel, Eberly, and Panageas (2007).

We measure U.S. households' holdings of accounts in retail banks using the Flow of Funds Accounts. ${ }^{10}$ From the Flow of Funds Accounts, we observe that U.S. households hold a large quantity of such accounts - on the order of $1 / 2$ to $2 / 3$ times annual personal consumption expenditure.

We use the implied average annual level of velocity of 1.5 to 2.0 as one statistic to guide our choice of $N$ and $\gamma$ for the quantitative results that follow. The other statistic that we use is based on our interpretation that the paycheck parameter in the model corresponds to regular wage and salary income automatically deposited in bank accounts in the data. Accordingly, as a baseline, we choose $\gamma=0.6$ to match the fraction of personal income that is received as wage and salary disbursements observed in the data. ${ }^{11}$

The steady-state velocity implied by our model is a simple function of the parameters $N$ and $\gamma$. In particular, holding $N$ fixed, the model's implications for steady-state velocity are an increasing function of the paycheck parameter $\gamma$ since the automatic deposit of paychecks into households' bank accounts allows for faster circulation of money. In the example with

\footnotetext{
${ }^{10}$ In terms of measuring the relative sizes of these accounts using data from the Flow of Funds Accounts, our interpretation corresponds to the following breakdown of the data presented in Table B.100 Balance Sheet of Households and NonProfit Organizations. Total Financial Assets for households are listed on line $8(\$ 45,405$ billion in 2007). We interpret the line 9 Deposits ( $\$ 7,334$ billion in 2007) as corresponding to assets held in bank accounts. This category includes checkable deposits and currency, time and savings deposits, and money market shares. We interpret the remaining financial assets listed under line 14 Credit Market Instruments, and lines 23-29 including, among other things, corporate equities, mutual fund shares, life insurance reserves, pension fund reserves, and equity in non-corporate business as corresponding to assets held in the households' brokerage accounts.

${ }^{11}$ From Table 2.1 of the National Income and Product Accounts, we observe that this fraction has been equal to $60 \%$ on average over the period 1959-2001.
} 
$u(c)=\log (c)$ and $\gamma=0$ that we used for intuition in the previous sections, with $\beta / \bar{\mu}$ close to one, aggregate velocity is given by $\bar{v}=2 /(N+1)$. With $\gamma>0$, for $\beta / \bar{\mu}$ close to one, aggregate velocity is well approximated by $\bar{v}=2 /(N+1)(1-\gamma)$, which increases as $\gamma$ increases.

Given our choice of $\gamma$ to match the fraction of personal income that is received as wage and salary disbursements, we choose the remaining parameter $N$ to match the average velocity of 1.5 on an annual basis. We choose the length of a period to be one month and as a baseline use $N=38$ so that with $\gamma=0.6$ the model produces an average velocity of 1.5 .

With these parameters, our model implies that households transfer money between their brokerage accounts and bank accounts very infrequently — on the order of only once every three years. Now we argue that this assumption is not inconsistent with the available microeconomic evidence on the frequency with which agents trade financial assets held outside of their bank accounts.

The first set of such microeconomic data concerns the frequency with which households trade equity. Such data are relevant since a household would have to trade equity to rebalance its portfolio between funds held in its bank account and equity held in its brokerage account. The Investment Company Institute (2002) conducted an extensive survey of households' holdings and trading of equity in 1998 and 2001. They report the frequency with which households traded stocks and stock mutual funds in each year. Averaging across the 1998 and 2001 surveys, $48 \%$ of the households neither bought nor sold stocks, and $68 \%$ of the households neither bought nor sold stock mutual funds in 1998 and 2001. Since a household would have to buy or sell some of these assets to transfer funds between these higher yielding assets held in a brokerage account and a lower yielding bank account, these data, interpreted in light of our model, would indicate choices of $N$ ranging from roughly 24 (for roughly $1 / 2$ of households trading these risky assets at least once within the year) to roughly 36 (for roughly $1 / 3$ of households trading within the year). ${ }^{12}$

\footnotetext{
${ }^{12}$ These data may also overstate the frequency with which households transfer funds between their equity accounts and their transactions accounts since some of the instances of equity trading are simply a reallocation of the equity portfolio. The Investment Company Institute reports that more than $2 / 3$ of those households that sold individual shares of stock in 1998 reinvested all of the proceeds, while $57 \%$ of those households that sold stock mutual funds reinvested all of the proceeds. In the context of our model, reallocation of the household portfolio in the asset market is costless and does not generate cash that can be used to purchase goods.
} 
The second set of microeconomic data is that presented by Vissing-Jorgensen (2002). She studies micro data on the frequency of household trading of stocks, bonds, mutual funds, and other risky assets obtained from the Consumer Expenditure Survey. In figure 6 in her paper, she shows the fraction of households who bought or sold one of these assets over the course of one year as a function of their financial wealth at the beginning of the year. She finds that the fraction of agents who traded one of these assets ranges from roughly $1 / 3$ to $1 / 2$ of the households owning these assets at the beginning of the year. Again, given our interpretation that households hold stocks, bonds, mutual funds and other risky assets in their brokerage accounts, these data would lead us to choose $N$ between 24 and 36 .

If a higher proportion of income is automatically available for spending (without the need for a transfer from the brokerage account), so that $\gamma$ is higher than 0.6 , then the chosen value for $N$ needs to be correspondingly higher to keep steady-state aggregate velocity constant. For example, to match $\bar{v}=1.5$ annual with the higher $\gamma=0.7$ needs about $N=52$ months. If we interpret our model in terms of a narrower monetary aggregate with correspondingly faster velocity, then the chosen value of $N$ needs to be lower. For example, to match $\bar{v}=2.0$ annual with our benchmark $\gamma=0.6$ requires $N=30$ months and to match $\bar{v}=4.0$ annual with $\gamma=0.6$ requires $N=15$ months.

\section{B. The response of velocity to U.S. money and consumption shocks}

We now study the implications of our model for velocity in the short-run when we feed in the money growth and aggregate consumption shocks observed in the U.S. data. We use monthly data on M2 as our measure of the monetary aggregate $M_{t}$, and we use monthly data on the deviation of the log of real personal consumption expenditure from a linear trend as our measure of the shocks to aggregate endowment $y_{t}$. To solve for households' decision rules in the model, we estimate a VAR relating the current money growth rate and aggregate consumption to 12 lags of these variables and use this VAR as the stochastic process governing the exogenous shocks. We then generate the model's implications for velocity by feeding in the actual series for these shocks. To compare the implications of our model for the dynamics

of money and velocity in the short-run to the data, we detrend the series implied by the model using the HP-filter. 
Consider the implications of our model with $N=38$ months and $\gamma=0.6$. In Figure 3, we show the HP-filtered series for velocity implied by our model with the corresponding HP-filtered series for velocity from the data. The correlation between velocity in the model and the data is 0.6. In the figure, we have used different scales in plotting the series from the model and the data. These different scales reflect the fact that the standard deviation of velocity in the model is only $40 \%$ of the standard deviation of velocity in the data.

Given that we have used nothing but steady-state information to choose the parameters of this model, we regard the high correlation between velocity from the model and the data as a remarkable success. Observe that if we had chosen $N=1$, as in a standard cash-inadvance model, velocity as implied by the model would be constant at one regardless of the shock process and, hence, the correlation between velocity in the model and velocity in the data would be zero. We interpret this finding as offering support for the hypothesis that a substantial portion of the negative correlation between the short-run movements of velocity and the ratio of money to consumption is due to the endogenous response of velocity to changes in the ratio of money to consumption.

We obtain broadly similar results with the alternative values of $N$ and $\gamma$ discussed above. For example, if we have $\gamma=0.7$ but increase $N$ to 52 to keep $\bar{v}=1.5$ annual, then the correlation of HP-filtered velocity implied by our model and the correlation of HP-filtered velocity in the data is still 0.51 (down from 0.60 for the benchmark parameters) while the standard deviation of velocity in the model rises slightly, to $45 \%$ of the standard deviation of velocity in the data. If instead we keep $\gamma=0.6$ but choose a lower $N=30$ to match a higher velocity of $\bar{v}=2.0$ annual, then the correlation of model and data velocity is 0.56 , almost the same as in the benchmark, but the standard deviation of velocity in the model falls to $32 \%$ of the data. Similarly, if we choose $N=15$ to match even higher velocity of $\bar{v}=4.0$ annual, then the correlation of model and data velocity falls slightly further to 0.48 while the standard deviation of velocity in the model falls to $21 \%$ of the data. Reducing $N$ to match the higher velocities implied by narrower monetary aggregates impairs the ability of the model to endogenously produce volatile velocity, but does not substantially alter the correlation between data and model velocity. 


\section{The response to a shock to the interest rate}

We now consider the response of inflation to a shock to the nominal interest rate. A large literature estimates the response of the macroeconomy to a monetary policy shock modeled as a shock to the Federal Funds rate. The consensus in this literature is that a monetary policy shock is associated with a persistent increase in the short-term nominal interest rate, a persistent decrease in the money supply and, at least initially, little or no response in the price level (Christiano, Eichenbaum, and Evans 1999). ${ }^{13}$

To simulate the effects of a monetary policy shock, we solve for a money growth path consistent with an exogenous, persistent movement in the short-term nominal interest rate. This raises two technical issues. First, recall from Proposition 1 that there is an indeterminacy in this model if the nominal interest rate is exogenous. In equilibrium, there are many paths for money growth, all consistent with the same exogenously specified path for nominal interest rates. ${ }^{14}$ In the quantitative experiment below, we resolve this indeterminacy in the same way that we did in Section 3. We choose the unique path for money growth that, on impact, leaves the price level unchanged. A second technical issue is that in this model the endogenous dynamics with an exogenous nominal interest rate last exactly $N$ periods. The matrix describing the equilibrium dynamics of endogenous variables has its $N$ eigenvalues all exactly equal to zero. This implies that, if the interest rate is set at its steady-state value but the initial distribution of money holdings is not, then steady-state will be reached in exactly $N$ periods. The repetition of the eigenvalues also implies that the matrix that described equilibrium dynamics is not diagonalizable, and hence, this model cannot be solved using standard methods such as those outlined by Blanchard and Kahn (1980) or Uhlig (1999). In an online technical appendix to this paper we develop a specific solution method for this model based on the use of the generalized Schur form that makes use of the information that the eigenvalues of the matrix describing equilibrium dynamics are all equal to zero. ${ }^{15}$

\footnotetext{
${ }^{13}$ See Cochrane (1994), Leeper, Sims, and Zha (1996), Uhlig (2005), and Christiano, Eichenbaum, and Evans (2005) for additional examples of such estimates.

${ }^{14}$ The indeterminacy result of Section 3 is for $u(c)=\log (c)$ and $\gamma=0$ but extends to the case of general isoelastic preferences and $\gamma>0$.

${ }^{15}$ This online technical appendix is available at http://pages.stern.nyu.edu/ cedmond/. We also found that direct methods based on use of the generalized Schur form, as suggested by Klein (2000) and others, did not correctly identify that the matrix describing equilibrium dynamics had eigenvalues all equal to zero. This appears to be a numerical issue since this methodology should work in cases with repeated eigenvalues.
} 
We now study the quantitative implications of our model with $N=38$ and $\gamma=0.6$, having solved for money growth consistent with the log of the short-term gross interest rate following an $\operatorname{AR}(1)$ process with persistence $\rho=0.87$. This persistence produces a response of the nominal interest rate to a monetary policy shock similar to that estimated by Christiano, Eichenbaum, and Evans (1999).

Figure 4 shows the impulse responses of inflation, money growth, and velocity growth following a persistent increase in the nominal interest rate. The model produces a persistent liquidity effect both in the sense that an increase in the nominal interest rate is associated with a fall in money growth and in the sense that an increase in the nominal interest rate is associated, at least initially, with an increase in the real interest rate of roughly the same size. While it is not plotted separately, the real interest rate in this figure can be read as the difference between the impulse response of the nominal interest rate and the impulse response for inflation. As is clear in the figure, the response of the real interest rate to the change in the nominal interest rate is quite persistent, and, as a result, inflation is persistently sluggish, responding only slowly to the increase in the nominal interest rate.

Figure 5 shows the same impulse responses but for the levels of the variables rather than their growth rates. The aggregate price level appears "sticky," showing little or no response to the shock to interest rates for at least the first 12 months. It is only after 12 months have passed that the money stock and the price level begin to rise together in the manner that would be expected in a flexible price model following a persistent increase in the nominal interest rate. This slow response of the price level simply reflects the persistently sluggish response of inflation.

This quantitative exercise indicates that our model can account for a substantial delay in the response of inflation to an exogenous shock to the nominal interest rate, and it does so because of the persistent response of the real interest rate to the change in the nominal interest rate.

\section{Conclusion}

In this paper, we have put forward a simple inventory-theoretic model of the demand for money and have shown, in that model, that the price level does not respond immediately 
to an exogenous increase in the money supply and that expected inflation does not respond immediately to an exogenous increase in the nominal interest rate. Instead, there is an extended period of price sluggishness that occurs because the exogenous increase in the money supply leads, at least initially, to an endogenous decrease in the velocity of money and an extended period of inflation sluggishness that occurs because of asset market segmentation. We have argued that if this simple model is used to analyze the dynamics of money and velocity using a relatively broad measure of money, then it produces sluggish responses of the price level and inflation similar to that estimated in the VAR literature on the response of the economy to monetary policy shocks.

In keeping this model simple, we have abstracted from a number of issues that might play an important role in the development of a more complete model. First, we have simply assumed that households have the opportunity to transfer funds between their brokerage and bank accounts only every $N$ periods and have not allowed households to alter the timing of these transactions after paying some fixed cost. This simplifying assumption allowed us to characterize equilibrium in an analytically tractable specification of our model. A model with explicit consideration of fixed costs of money transfers between accounts must be computed numerically. For work along these lines, see Khan and Thomas (2007). In their benchmark calibrated example, they find that these costs substantially reinforce the sluggishness of prices and the persistence of liquidity effects relative to that seen in our model. ${ }^{16}$

Second, we have simply assumed that output is exogenous so as to focus on the impact of monetary policy on prices and inflation. The impact of monetary policy shocks on output in a version of our model in which production is endogenous is an important area for future research. We have shown that monetary policy shocks have a direct impact on real asset prices in general and on real interest rates in particular. In a model with endogenous production, these changes in real asset prices would induce firms and workers to shift production and investment through time. The specific results that would be obtained would clearly depend on the exact specification of the production structure of the model. In recent work, Edmond

\footnotetext{
${ }^{16}$ As Khan and Thomas (2007) emphasize, this result is sensitive to the shape of the idiosyncratic distribution of fixed costs facing households. The reason for this sensitivity is a "selection effect" familiar from models of price setting subject to menu costs.
} 
(2003) and King and Thomas (2007) have begun to consider such models.

There is a large literature that looks to model the sluggish responses of prices and inflation in an alternative framework in which prices are sticky because firms adjust prices infrequently. ${ }^{17}$ Our results on the sluggish responses of prices to changes in money and inflation to changes in the nominal interest rate arise from theoretical mechanisms that are unrelated to firms' price setting decisions. Moreover, the empirical phenomena that motivate our study are also unrelated to the extent of nominal rigidities.

Consider first our results on the sluggish response of prices to changes in the stock of money. In our model, prices respond sluggishly to changes in money because nominal expenditure responds sluggishly to changes in money — velocity, which is the ratio of nominal expenditure to money, falls when money rises. The response of nominal expenditure to a change in the stock of money is a feature of money demand, not of the extent of nominal rigidities in terms of firms' price setting decisions. For example, if one posits money demand that is interest inelastic as part of a sticky price model, then nominal expenditure will respond one-for-one with the stock of money regardless of the extent of nominal rigidities assumed in the model. Thus modeling money demand in our way in a sticky price set-up — where changes in nominal demand become changes in real output - implies that a given money supply shock has a smaller real effect on impact but a more persistent real effect than obtained using an otherwise standard specification of money demand. Researchers using sticky price models may find it useful to incorporate our model of money demand when they look to account for the impact of a change in the stock of money on the economy. It is clear from our Figure 1 that this sluggish response of nominal expenditure to money is an important component of understanding the dynamics of prices and money in the unconditional U.S. data. VAR results in Altig et al. (2004) indicate that nominal expenditure also responds sluggishly to a shock to monetary policy.

Consider next the relationship between our results and the sluggish response of inflation to changes in the nominal interest rate relative to those in sticky price models. Our

\footnotetext{
${ }^{17}$ This literature includes models in which firms set prices according to time-dependent rules (Fischer 1977 , Taylor 1980, Rotemberg 1982, Calvo 1983), state-dependent rules (Caplin and Leahy 1991, Dotsey, King, and Wolman 1999, Midrigan 2006, Golosov and Lucas 2007), or, more recently, on the basis of slowly updated information (Mankiw and Reis 2002, Woodford 2003a).
} 
model is able to produce a sluggish response of inflation to a persistent shock to the nominal interest rate due to the segmentation of asset markets. The money injections that implement a persistent change in the nominal interest rate also lead to a persistent change in the real interest rate of nearly the same magnitude. Sluggish inflation then follows directly, not as a consequence of sticky prices, but instead as a consequence of the standard Fisher equation linking nominal interest rates, real interest rates, and inflation.

In contrast, standard sticky price models have serious problems in reproducing the estimated responses of inflation to a shock to monetary policy modeled as a persistent shock to the nominal interest rate. Mankiw (2001), for example, discusses how a standard sticky price model predicts that the largest response of inflation to a persistent shock to the nominal interest rate occurs on impact, and not in a delayed fashion. He uses this observation to argue for a model with "sticky information". Sims (1998) makes a similar argument.

The difficulty that sticky price models face in generating sluggish inflation arises from the fact that standard sticky-price models build on a representative household framework linking the real interest rate to the growth of marginal utility for the representative household, and hence aggregate consumption, through a consumption Euler equation. Thus, in these models, if expected inflation responds sluggishly to a change in the nominal interest rate, then the growth rate of marginal utility for the representative household must respond strongly to a change in the nominal interest rate. Hence, capturing simultaneously a sluggish response of expected inflation and aggregate consumption to a change in the short-term nominal interest rate has been a challenge for these models. Frontier sticky price models, such as Christiano, Eichenbaum, and Evans (2005), use time non-separable preferences and an elaborate set of adjustment costs and shocks to help their model reproduce a specific set of impulse responses, including the sluggish response of inflation. Canzoneri, Cumby, and Diba (2007), however, observe that standard sticky price models equate the nominal interest rate targeted by the central bank with the interest rate implied by the representative household's consumption Euler equation and that this assumption fails quite dramatically in the data even if one considers a wide array of time non-separable preferences for the household. They find a negative correlation between the Federal Funds rate in the data and the short-term nominal interest rates implied by a wide variety of sticky-price models' consumption Euler equations. 
By contrast, our model abandons the assumption of a representative household for pricing assets. In our model, the real interest rate is linked to the growth of marginal utility for active households, not for a representative household consuming aggregate consumption. Hence, as we have seen in our model, we can produce a sluggish response of expected inflation to a change in the nominal interest rate even if aggregate consumption is constant and hence has no response at all to a change in the nominal interest rate. Researchers using models with nominal rigidities may find it useful to incorporate asset market segmentation of the kind we examine here in their models in addressing some of the difficulties their models have with the consumption Euler equation.

\section{References}

Abel, Andrew B., Janice C. Eberly, and Stavros Panageas. 2007. Optimal inattention to the stock market. American Economic Review 97 (May): 244-249.

Altig, David, Lawrence J. Christiano, Martin Eichenbaum, and Jesper Linde. 2004. Firmspecific capital, nominal rigidities and the business cycle. Working Paper 04-16. Federal Reserve Bank of Cleveland.

Alvarez, Fernando, and Andrew Atkeson. 1997. Money and exchange rates in the GrossmanWeiss-Rotemberg model. Journal of Monetary Economics 40 (December): 619-640.

Alvarez, Fernando, Andrew Atkeson, and Patrick J. Kehoe. 2002. Money, interest rates, and exchange rates with endogenously segmented markets. Journal of Political Economy 110 (February): 73-112.

Alvarez, Fernando, Andrew Atkeson, and Patrick J. Kehoe. 2007. Time-varying risk, interest rates, and exchange rates in general equilibrium. Research Department Staff Report 371. Federal Reserve Bank of Minneapolis.

Alvarez, Fernando, Robert E. Lucas, Jr., and Warren E. Weber. 2001. Interest rates and inflation. American Economic Review 91 (May): 219-225.

Barro, Robert J. 1976. Integral constraints and aggregation in an inventory model of money demand. Journal of Finance 31 (March): 77-88.

Baumol, William J. 1952. The transactions demand for cash: an inventory theoretic approach. Quarterly Journal of Economics 66 (November): 545-556. 
Blanchard, Olivier Jean, and Charles M. Kahn. 1980. The solution of linear difference models under rational expectations. Econometrica 48 (July): 1305-1311.

Calvo, Guillermo A. 1983. Staggered prices in a utility maximizing framework. Journal of Monetary Economics 12 (September): 383-398.

Canzoneri, Matthew B., Robert E. Cumby, and Behzad T. Diba. 2007. Euler equations and money market interest rates: a challenge for monetary policy models. Journal of Monetary Economics 54 (October): 1863-1881.

Caplin, Andrew, and John Leahy. 1991. State-dependent pricing and the dynamics of money and output. Quarterly Journal of Economics 106 (August): 683-708.

Chatterjee, Satyajit, and Dean Corbae. 1992. Endogenous market participation and the general equilibrium value of money. Journal of Political Economy 100 (June): 615646.

Chiu, Jonathan. 2007. Endogenously segmented asset market in an inventory-theoretic model of money demand. Working Paper 2007-46. Bank of Canada.

Christiano, Lawrence, Martin Eichenbaum, and Charles Evans. 1999. Monetary policy shocks: what have we learned and to what end? In Handbook of Macroeconomics, ed. Michael Woodford and John Taylor. Amsterdam: North-Holland.

Christiano, Lawrence, Martin Eichenbaum, and Charles Evans. 2005. Nominal rigidities and the dynamic effects of a shock to monetary policy. Journal of Political Economy 113 (February): 1-45.

Clark, Timothy, Astrid Dick, Beverly Hirtle, Kevin J. Stiroh, and Robard Williams. 2007. The role of retail banking in the U.S. banking industry: risk, return, and industry structure. Federal Reserve Bank of New York Economic Policy Review 13 (December): 39-56.

Cochrane, John H. 1994. Shocks. Carnegie-Rochester Conference Series on Public Policy 41 (December): 295-364.

Dotsey, Michael, Robert G. King, and Alexander L. Wolman. 1999. State-dependent pricing and the general equilibrium dynamics of money and output. Quarterly Journal of Economics 114 (May): 655-690.

Duffie, Darrell, and Tong-Sheng Sun. 1990. Transactions costs and portfolio choice in 
a discrete-continuous-time setting. Journal of Economic Dynamics and Control 14 (February): 35-51.

Edmond, Chris. 2003. Sticky prices versus sticky demand. Manuscript. University of Melbourne.

Federal Reserve Board. 2002. Flow of Funds Accounts of the United States.

Fischer, Stanley. 1977. Long-term contracts, rational expectations, and the optimum money supply rule. Journal of Political Economy 85 (February): 191-205.

Golosov, Mikhail, and Robert E. Lucas, Jr. 2007. Menu costs and Phillips curves. Journal of Political Economy 115 (April): 171-199.

Grossman, Sanford J., and Laurence Weiss. 1983. A transactions-based model of the monetary transmission mechanism. American Economic Review 73 (December): 871-880.

Investment Company Institute. 2002. Equity Ownership in America.

Jovanovic, Boyan. 1982. Inflation and welfare in the steady state. Journal of Political Economy 90 (June): 561-577.

Khan, Aubhik, and Julia K. Thomas. 2007. Inflation and interest rates with endogenous market segmentation. Working Paper 07-1. Federal Reserve Bank of Philadelphia.

King, Robert G., and Julia K. Thomas. 2007. Breaking the new Keynesian dichotomy: asset market segmentation and the monetary transmission mechanism. Manuscript. Ohio State University.

Klein, Paul. 2000. Using the generalized Schur form to solve a multivariate linear rational expectations model. Journal of Economic Dynamics and Control 24 (September): 1405-1423.

Leeper, Eric M., Christopher A. Sims, and Tao Zha. 1996. What does monetary policy do? Brookings Papers on Economic Activity 2: 1-78.

Lucas, Robert E., Jr. 1978. Asset prices in an exchange economy. Econometrica 46 (November): $1429-1445$.

Mankiw, N. Gregory. 2001. The inexorable and mysterious tradeoff between inflation and unemployment. Economic Journal 111 (May): C45-C61.

Mankiw, N. Gregory, and Ricardo Reis. 2002. Sticky information versus sticky prices: a proposal to replace the new Keynesian Phillips curve. Quarterly Journal of Economics 
117 (November): 1295-1328.

Midrigan, Virgiliu. 2006. Menu costs, multi-product firms, and aggregate fluctuations. Manuscript. Federal Reserve Bank of Minneapolis.

Ravn, Morten O., and Harald Uhlig. 2002. On adjusting the Hodrick-Prescott filter for the frequency of observations. Review of Economics and Statistics 84 (May): 371-380.

Romer, David. 1986. A simple general equilibrium version of the Baumol-Tobin model. Quarterly Journal of Economics 101 (November): 663-686.

Rotemberg, Julio J. 1982. Monopolistic price adjustment and aggregate output. Review of Economic Studies 49 (October): 517-531.

Rotemberg, Julio J. 1984. A monetary equilibrium model with transactions costs. Journal of Political Economy 92 (February): 40-58.

Silva, André C. 2008. Prices and money after interest rate shocks with endogenous market segmentation. Manuscript, Universidade Nova de Lisboa.

Sims, Christopher A. 1998. Stickiness. Carnegie-Rochester Series on Public Policy 49 (December): $317-356$.

Taylor, John B. 1980. Aggregate dynamics and staggered contracts. Journal of Political Economy 88 (February): 1-23.

Tobin, James. 1956. The interest-elasticity of the transactions demand for cash. Review of Economics and Statistics 38 (August): 241-247.

Uhlig, Harald. 1999. A toolkit for analysing nonlinear dynamic stochastic models easily. In Computational Methods for the Study of Dynamic Economies, ed. Ramon Marimon and Andrew Scott. New York: Oxford University Press.

Uhlig, Harald. 2005. What are the effects of monetary policy on output? Results from an agnostic identification procedure. Journal of Monetary Economics 52 (March): 382-419.

Vissing-Jorgensen, Annette. 2002. Towards an explanation of household portfolio choice heterogeneity: nonfinancial income and participation cost structures. Working Paper 8884. National Bureau of Economic Research.

Woodford, Michael. 2003a. Imperfect common knowledge and the effects of monetary policy. In Knowledge, Information, and Expectations in Modern Macroeconomics, ed. 
Philippe Aghion, Roman Frydman, Joseph Stiglitz, and Michael Woodford. Princeton: Princeton University Press.

Woodford, Michael. 2003b. Interest and Prices: Foundations of a Theory of Monetary Policy. Princeton: Princeton University Press. 


\section{Appendix}

\section{A1. Data}

All data are monthly 1959:1-2006:12 and seasonally adjusted. We measure the price level $P$ as the personal consumption expenditures chain-type price index with a base year of 2000 from the Bureau of Economic Analysis (BEA). We measure real consumption $c$ as personal consumption expenditure on nondurables and services from the BEA deflated by $P$. We measure the money supply $M$ as the M2 stock from the Board of Governors of the Federal Reserve System. We define velocity as $v \equiv P c / M$.

\section{Alternative measures of the short-run correlation of money and velocity}

Here we document the robustness of the negative correlation between $\log (M / c)$ and $\log (v)$ using alternative detrending methods to characterize the short-run fluctuations in money and velocity. We report statistics for HP-filtered data based on the smoothing parameter $\lambda=1600 \times 3^{4}$ recommended by Ravn and Uhlig (2002) for monthly data. These are the statistics reported in the main text. In Table 1, we also report statistics for the lower smoothing parameter $\lambda=1600 \times 3^{2}$ and for monthly differences and annual differences. No matter how the short-run fluctuations are measured, we find that there is a pronounced negative correlation between $\log (M / c)$ and $\log (v)$ and that the standard deviation of $\log (v)$ is almost as high as or higher than the standard deviation of $\log (M / c)$.

\begin{tabular}{l|rr|rr} 
& \multicolumn{2}{|c|}{ HP-filtered } & \multicolumn{2}{c}{ differenced } \\
& $1600 \times 3^{2}$ & $1600 \times 3^{4}$ & monthly & annual \\
\hline \hline Correlation & -0.91 & -0.86 & -0.88 & -0.63 \\
Standard deviation & 1.25 & 1.33 & 1.01 & 0.98
\end{tabular}

Table 1: Correlation and relative standard deviation of $\log (v)$ to $\log (M / c)$ based on alternative measures of short-run fluctuations.

\section{Evidence on opportunity cost of holding broad money}

We measure the opportunity costs of monetary assets using data collected by the Monetary Services Index project of the Federal Reserve Bank of St Louis. We measure the opportunity cost of an asset as the short-term Treasury rate less the own rate of return on the asset in question. We take the short-term Treasury rate and own rates of return on currency and demand deposits from the spreadsheet ADJSAM.WKS available from the website of the Federal Reserve Bank of St Louis. We take the own rate of return on M2 from the Board of Governors of the Federal Reserve System. All opportunity cost data are monthly 1959:1-2006:2 and seasonally adjusted.

As is clear from Table 2, the average opportunity cost of holding demand deposits and 


\begin{tabular}{lccc} 
& $1959-2006$ & $1959-1990$ & $1990-2006$ \\
\hline \hline Currency & 4.91 & 5.61 & 3.45 \\
Demand deposits & 1.80 & 2.25 & 0.85 \\
M2 & 2.08 & 2.30 & 1.64
\end{tabular}

Table 2: Opportunity costs of various monetary assets. All opportunity costs measured as the average short-term Treasury rate less own rate reported in percentage points.

M2 is roughly similar, on the order of 200 basis points. Both opportunity costs have fallen somewhat in recent years.

\section{A2. Algebra of steady-state money distribution and elasticities}

Let the length of a period be $\Delta>0$ measured in fractions of a year. Let the length of time between periods of activity be $T$ such that the number of periods between periods of inactivity is $N=T / \Delta$. Let period utility be $u(c)=\log (c)$ and set the paycheck parameter to $\gamma=0$. In this setting, individual velocity in period $t$ is time-invariant and given by $v(s) \Delta=\left(1-\beta^{\Delta}\right) /\left(1-\beta^{\Delta(N-s)}\right)$ for $s=0,1, \ldots, N-1$.

For households $s=1, \ldots, N-1$ the distribution of money holdings satisfies:

$$
\frac{M_{t}(s)}{M_{t}}=[1-v(s-1) \Delta] \frac{M_{t-1}(s-1)}{M_{t}} \frac{1}{\mu_{t}^{\Delta}}
$$

with money market clearing implying:

$$
\frac{1}{N} \frac{M_{t}(0)}{M_{t}}=1-\frac{1}{N} \sum_{s=1}^{N-1}[1-v(s-1) \Delta] \frac{M_{t-1}(s-1)}{M_{t}} \frac{1}{\mu_{t}^{\Delta}}
$$

\section{Steady-state money distribution and aggregate velocity}

Now consider a steady-state with $\mu_{t}=\bar{\mu}$. Iterating on the steady-state version of (A1) and using the formula for individual velocity shows that the steady-state money holdings of household $s$ are related to the holdings of an active household by:

$$
\frac{M(s)}{M}=\frac{1}{\bar{\mu}^{\Delta s}} \prod_{i=0}^{s-1}(1-v(i) \Delta) \frac{M(0)}{M} .
$$

And since

$$
\prod_{i=0}^{s-1}(1-v(i) \Delta)=\prod_{i=0}^{s-1} \beta^{\Delta} \frac{1-\beta^{\Delta(N-i-1)}}{1-\beta^{\Delta(N-i)}}=\beta^{\Delta s} \frac{1-\beta^{\Delta(N-s)}}{1-\beta^{\Delta N}},
$$


we have:

$$
\frac{M(s)}{M}=\left(\frac{\beta}{\bar{\mu}}\right)^{\Delta s} \frac{1-\beta^{\Delta(N-s)}}{1-\beta^{\Delta N}} \frac{M(0)}{M} .
$$

We now need to find $M(0) / M$. We do this using steady-state money market clearing:

$$
\frac{1}{N} \frac{M(0)}{M}=1-\frac{1}{N} \sum_{s=1}^{N-1} \frac{M(s)}{M}=1-\frac{1}{N} \sum_{s=1}^{N-1} \frac{M(0)}{M}\left(\frac{\beta}{\bar{\mu}}\right)^{\Delta s} \frac{1-\beta^{\Delta(N-s)}}{1-\beta^{\Delta N}},
$$

and so:

$$
1=\frac{1}{N} \frac{M(0)}{M} \sum_{s=0}^{N-1}\left(\frac{\beta}{\bar{\mu}}\right)^{\Delta s} \frac{1-\beta^{\Delta(N-s)}}{1-\beta^{\Delta N}} .
$$

Computing the sums and rearranging gives the solution:

$$
\frac{1}{N} \frac{M(0)}{M}=\left(1-\beta^{\Delta N}\right)\left[\frac{1-(\beta / \bar{\mu})^{\Delta N}}{1-(\beta / \bar{\mu})^{\Delta}}-\beta^{\Delta N} \frac{1-(1 / \bar{\mu})^{\Delta N}}{1-(1 / \bar{\mu})^{\Delta}}\right]^{-1} .
$$

Plugging this formula for $M(0) / M$ into equation (A4) gives the complete solution for the steady-state distribution of money holdings. Steady-state aggregate velocity at an annual rate is then given by:

$$
\bar{v}=\frac{1}{N} \sum_{s=0}^{N-1} v(s) \frac{M(s)}{M} .
$$

We can use the formula for individual velocity in each period to simplify the terms in the sum. For each $s$ we have:

$$
v(s) \frac{M(s)}{M}=\frac{1}{\Delta} \frac{1-\beta^{\Delta}}{1-\beta^{\Delta(N-s)}}\left(\frac{\beta}{\bar{\mu}}\right)^{\Delta s} \frac{1-\beta^{\Delta(N-s)}}{1-\beta^{\Delta N}} \frac{M(0)}{M}=\frac{1}{\Delta} \frac{1-\beta^{\Delta}}{1-\beta^{\Delta N}}\left(\frac{\beta}{\bar{\mu}}\right)^{\Delta s} \frac{M(0)}{M} .
$$

And so, using the formula for $M(0) / M$ given in equation (A7) and then summing over $s$, we have:

$$
\bar{v}=\frac{1-\beta^{\Delta}}{\Delta}\left[1-\beta^{\Delta N}\left(\frac{1-(1 / \bar{\mu})^{\Delta N}}{1-(1 / \bar{\mu})^{\Delta}} \frac{1-(\beta / \bar{\mu})^{\Delta}}{1-(\beta / \bar{\mu})^{\Delta N}}\right)\right]^{-1} .
$$

To develop intuition, we simplify these formulas by studying a steady-state with $\bar{\mu}=1$ in the limit as $\beta \rightarrow 1$. We begin with the further special case of $\Delta=1$ month so that we can quickly derive the main formulas used in the text and then return to the case of general $\Delta>0$ at the end. 
With this extra structure, the steady-state money holdings of household $s$ are related to the holdings of an active household by:

$$
\frac{M(s)}{M}=\frac{N-s}{N} \frac{M(0)}{M}
$$

And so, on using this formula in money market clearing, we also get $M(0) / M=2 N /(N+1)$ so that we have the complete solution for the distribution of money holdings:

$$
\frac{M(s)}{M}=2 \frac{N-s}{N+1}
$$

for $s=0,1, \ldots, N-1$. Steady-state aggregate velocity is then:

$$
\bar{v}=\frac{1}{N} \sum_{s=0}^{N-1} v(s) \frac{M(s)}{M}=\frac{1}{N} \sum_{s=0}^{N-1} \frac{2}{N-s} \frac{N-s}{N+1}=\frac{2}{N+1},
$$

as used in the main text.

\section{Elasticities with respect to money growth}

Continuing with this special case of $\Delta=1$ month, we now derive the elasticity of aggregate velocity with respect to money growth. Specifically using money market clearing and the law of motion for the money holdings we have:

$$
\begin{aligned}
v_{t} & =\frac{1}{N} \sum_{s=0}^{N-1} v(s) \frac{M_{t}(s)}{M_{t}} \\
& =v(0)\left[1-\frac{1}{N} \sum_{s=1}^{N-1} \frac{M_{t}(s)}{M_{t}}\right]+\frac{1}{N} \sum_{s=1}^{N-1} v(s) \frac{M_{t}(s)}{M_{t}} \\
& =v(0)+\frac{1}{N} \sum_{s=1}^{N-1}[v(s)-1] \frac{M_{t}(s)}{M_{t}} \\
& =v(0)+\frac{1}{N} \sum_{s=1}^{N-1}[v(s)-1][1-v(s-1)] \frac{M_{t-1}(s-1)}{M_{t-1}} \frac{1}{\mu_{t}} .
\end{aligned}
$$

And so:

$$
v_{t} \mu_{t}=v(0) \mu_{t}+\frac{1}{N} \sum_{s=1}^{N-1}[v(s)-1][1-v(s-1)] \frac{M_{t-1}(s-1)}{M_{t-1}},
$$

which gives the key result:

$$
\frac{\partial}{\partial \mu_{t}}\left(v_{t} \mu_{t}\right)=v(0)
$$


a constant for all $t$. Using the product rule $\partial\left(v_{t} \mu_{t}\right) / \partial \mu_{t}=\left(\partial v_{t} / \partial \mu_{t}\right) \mu_{t}+v_{t}$ we can solve for the elasticity in terms of $v(0)$, a known constant, and aggregate velocity. We evaluate this elasticity at steady-state $v_{t}=\bar{v}$ to get:

$$
\frac{\partial \log (v)}{\partial \log (\mu)}=\frac{v(0)}{\bar{v}}-1=-\frac{1}{2} \frac{N-1}{N} .
$$

And since the aggregate endowment $y$ is constant, the elasticity of inflation with respect to money growth evaluated at steady-state is:

$$
\frac{\partial \log (\pi)}{\partial \log (\mu)}=\frac{\partial \log (v)}{\partial \log (\mu)}+1=\frac{v(0)}{\bar{v}}=\frac{1}{2} \frac{N+1}{N} .
$$

We now derive the elasticity of the share of money held by active households with respect to money growth. Multiplying equation (A2) by $M_{t}$ and differentiating both sides with respect to $M_{t}$ we get:

$$
\frac{\partial M_{t}(0)}{\partial M_{t}}=N
$$

So that evaluated at steady-state:

$$
\frac{\partial \log (M(0))}{\partial \log (\mu)}=N \frac{M}{M(0)}=N \frac{N+1}{2 N}=\frac{N+1}{2} .
$$

Now let $m(0) \equiv M(0) / M$ denote the steady-state money share. Then we have:

$$
\frac{\partial \log (m(0))}{\partial \log (\mu)}=\frac{\partial \log (M(0))}{\partial \log (\mu)}-1=\frac{N+1}{2}-1=\frac{N-1}{2} .
$$

To obtain the expressions with arbitrary $\Delta$ used in the main text, set $N=T / \Delta$ in equations (A14)-(A16). More formally, use the expression for $\bar{v}$ in equation (A9) and calculate the limit as $\beta / \bar{\mu} \rightarrow 1$ using l'Hôpital's rule.

\section{A3. Dynamic response of velocity to a money growth shock}

Here we analytically characterize the impulse response of velocity to a money growth shock. The dynamics of velocity following a money growth shock are determined by the subsequent evolution of the distribution of money over time. It is easiest to analyze the dynamics of velocity following a shock in a log-linearized version of the model. We proceed in two steps. First, we provide an autoregressive moving average (ARMA) representation of the dynamics of the money distribution. Second, we map the ARMA representation into a formula for the impulse response of velocity that is exact (up to the log-linearization) for the first $N-1$ periods after a shock. For simplicity we consider only the special case of a period 
length $\Delta=1$ month.

\section{ARMA representation}

Two sets of equations govern the dynamics of the distribution of money. First, there is an equation requiring that the sum of the log deviations of the fractions of money held by agents of type $s$ is zero:

$$
0=m(0) \hat{m}_{t}(0)+\sum_{s=1}^{N-1} m(s) \hat{m}_{t}(s)
$$

where steady-state money shares are $m(s) \equiv M(s) / M$ and $\hat{m}_{t}(s) \equiv \log \left[m_{t}(s) / m(s)\right]$. Second, there is a set of equations for $s=1, \ldots, N-1$ governing the evolution of the money shares:

$$
\hat{m}_{t}(s)=\hat{m}_{t-1}(s-1)-\hat{\mu}_{t}
$$

where these equations follow from the fact that individual velocities $v(s)$ are time-invariant. Rearranging the first equation and using $m(s)=2(N-s) /(N+1)$ we have for active households:

$$
\hat{m}_{t}(0)=-\sum_{s=1}^{N-1} \frac{m(s)}{m(0)} \hat{m}_{t}(s)=-\sum_{s=1}^{N-1} \frac{N-s}{N} \hat{m}_{t}(s),
$$

and after iterating on the transitions for inactive households:

$$
\hat{m}_{t}(s)=\hat{m}_{t-s}(0)-\sum_{k=1}^{s} \hat{\mu}_{t-k+1}
$$

for $s=1, \ldots, N-1$. Combining these gives an ARMA representation of the dynamics of the money distribution:

$$
\hat{m}_{t}(0)=-\sum_{s=1}^{N-1} \frac{N-s}{N} \hat{m}_{t-s}(0)+\sum_{s=1}^{N-1} \frac{N-s}{N} \sum_{k=1}^{s} \hat{\mu}_{t-k+1} .
$$

\section{Impulse response for velocity}

The log deviation of velocity can be written:

$$
\hat{v}_{t}=\frac{1}{N} \sum_{s=0}^{N-1} \hat{m}_{t}(s)
$$


using $v(s) m(s)=2 /(N+1)=\bar{v}$ for all $s$. Differencing this once and simplifying gives

$$
\Delta \hat{v}_{t}=\frac{1}{N} \sum_{s=0}^{N-1} \Delta \hat{m}_{t}(s)=\frac{1}{N}\left[\hat{m}_{t}(0)-\hat{m}_{t-N}(0)-(N-1) \hat{\mu}_{t}+\sum_{s=1}^{N-1} \hat{\mu}_{t-s}\right]
$$

which repeatedly uses $\hat{m}_{t-1}(s-1)=\hat{m}_{t}(s)+\hat{\mu}_{t}$ to cancel terms in the sum. Let the economy start in steady-state for $t<0$ and consider a given shock $\hat{\mu}_{t}$ at date $t$ with $\hat{\mu}_{t+k}=0$ for all $k>0$. For the first $N-1$ periods after a shock, the terms $\hat{m}_{t-N}(0)$ and the sum $\sum_{s=1}^{N-1} \hat{\mu}_{t-s}$ are zero so that $\Delta \hat{v}_{t}=\left[\hat{m}_{t}(0)-(N-1) \hat{\mu}_{t}\right] / N$. We can solve this for $\hat{m}_{t}(0)=N \Delta \hat{v}_{t}+(N-1) \hat{\mu}_{t}$ and use the ARMA representation for the money share of active households to get an ARMA representation of velocity growth that is exact for the first $N-1$ periods:

$$
\Delta \hat{v}_{t}=-\sum_{s=1}^{N-1} \frac{N-s}{N} \Delta \hat{v}_{t-s}-\frac{1}{2} \frac{N-1}{N} \hat{\mu}_{t}
$$

(using $\hat{\mu}_{t-s}=0$ for the first $N-1$ periods). Rearranging terms to write this in levels we get:

$$
\hat{v}_{t}=\frac{1}{N} \sum_{s=1}^{N-1} \hat{v}_{t-s}-\frac{1}{2} \frac{N-1}{N} \hat{\mu}_{t}
$$

(this time using $\hat{v}_{t-N}=0$ for the first $N-1$ periods). When $N$ is large so that $(N-1) / N \approx 1$ this implies the impulse response of the log of velocity over the first $N-1$ periods is given by

$$
\hat{v}_{t+k}=\frac{1}{2}\left(1+\frac{1}{N}\right)^{k+1}-1
$$

This starts with $\hat{v}_{t}=-1 / 2$, for large $N$ it crosses zero at roughly $k=N \log (2)$ and then rises above zero until $k=N$.

\section{A4. Proof of indeterminacy proposition}

Using that $u(c)=\log (c)$ and $\gamma=0$ so that $P_{t} c_{t}(0)=v(0) M_{t}(0)$, and that:

$$
\frac{u^{\prime}\left(c_{t}(0)\right)}{P_{t}}=\frac{1}{c_{t}(0) P_{t}}=\frac{1}{v(0) M_{t}(0)}
$$

the sequence of $M_{t}(0)$ that supports the interest rate $\left\{i_{t}^{*}\right\}_{t=0}^{\infty}$ must satisfy:

$$
\frac{M_{t+1}(0)}{M_{t}(0)}=\left(1+i_{t}^{*}\right) \beta, \quad t=0,1, \ldots
$$


or:

$$
M_{t+1}(0)=M_{0}(0) \beta^{t} \prod_{j=0}^{t}\left(1+i_{j}^{*}\right) .
$$

For future reference, we can write equation (A18) as:

$$
M_{t-1-s}(0)=M_{0}(0) \beta^{t-1-s-1} \prod_{j=0}^{t-1-s-1}\left(1+i_{j}^{*}\right)
$$

which applies if $t-1-s \geq 0$ or $s \leq t-1$.

Now again using that $u(c)=\log (c)$ and $\gamma=0$ we have:

$$
M_{t}(s)=(1-v(s-1)) M_{t-1}(s-1), \quad s=1, \ldots, N
$$

which we can substitute into:

$$
M_{t}(0)=N M_{t}-\sum_{s=1}^{N-1}(1-v(s-1)) M_{t}(s-1),
$$

to obtain:

$$
M_{t}(0)=N\left(M_{t}-M_{t-1}\right)+\sum_{s=0}^{N-1} \theta_{s} M_{t-1-s}(0),
$$

where the coefficients $\theta_{s}$ are given by $\theta_{s} \equiv v(s)\left[\prod_{j=0}^{s-1}(1-v(j))\right]>0$.

It is easy to verify that any sequence of $\left\{M_{t}-M_{t-1}\right\}$ for $t \geq 0$ and $\left\{M_{t}(0)\right\}$ for $t \geq-N+1$ that solves equation (A20) completely characterizes an equilibrium.

Now we specialize equation (A20) for three different types of time periods. For $t=0$ we have:

$$
M_{0}(0)=N\left(M_{0}-M_{-1}^{*}\right)+\sum_{s=0}^{N-1} \theta_{s} M_{-1-s}^{*}(0) .
$$

For $t=1,2, \ldots, N-1$ we can break the sum in two parts and use the expression for 
$M_{t-1-s}(0)$ in terms of interest rates, equation (A19), so we have:

$$
\begin{aligned}
& M_{t}(0) \\
= & N\left(M_{t}-M_{t-1}\right)+\sum_{s=0}^{t-1} \theta_{s} M_{t-1-s}(0)+\sum_{s=t}^{N-1} \theta_{s} M_{t-1-s}^{*}(0) \\
= & N\left(M_{t}-M_{t-1}\right)+\sum_{s=0}^{t-1} \theta_{s} M_{0}(0) \beta^{t-1-s-1} \prod_{j=0}^{t-1-s-1}\left(1+i_{j}^{*}\right)+\sum_{s=t}^{N-1} \theta_{s} M_{t-1-s}^{*}(0),
\end{aligned}
$$

and using the expression for the interest rate equation (A18) again:

$$
\begin{aligned}
& M_{0}(0) \beta^{t-1} \prod_{j=0}^{t-1}\left(1+i_{j}^{*}\right) \\
= & N\left(M_{t}-M_{t-1}\right)+\sum_{s=0}^{t-1} \theta_{s} M_{0}(0) \beta^{t-1-s-1} \prod_{j=0}^{t-1-s-1}\left(1+i_{j}^{*}\right)+\sum_{s=t}^{N-1} \theta_{s} M_{t-1-s}^{*}(0) .
\end{aligned}
$$

Finally, for $t=N, N+1, \ldots$ we have:

$$
M_{t}(0)=N\left(M_{t}-M_{t-1}\right)+\sum_{s=0}^{N-1} \theta_{s} M_{0}(0) \beta^{t-1-s-1} \prod_{j=0}^{t-1-s-1}\left(1+i_{j}\right)
$$

and inserting the expression for $M_{t}(0)$ based on the interest rates:

$$
\begin{aligned}
& M_{0}(0) \beta^{t-1} \prod_{j=0}^{t-1}\left(1+i_{j}^{*}\right) \\
= & N\left(M_{t}-M_{t-1}\right)+\sum_{s=0}^{N-1} \theta_{s} M_{0}(0) \beta^{t-1-s-1} \prod_{j=0}^{t-1-s-1}\left(1+i_{j}\right) .
\end{aligned}
$$

Now we are ready to construct the path of the remaining variables for an equilibrium that support the interest rate path $\left\{i_{t}^{*}\right\}_{t=0}^{\infty}$. We do this in three steps, one for each type of time period. We do this for an arbitrary value of $M_{0}$.

Step a. Solve for $M_{0}(0)$. For $t=0, M_{0}(0)$ is a function of predetermined variables, $M_{-1}^{*}, M_{j}^{*}(0)$ for $j<0$, and $M_{0}$. Thus for the given value of $M_{0}$ there is a unique value of $M_{0}(0)$.

Step $b$. Solve for $M_{t}(0)$ and $M_{t}$ for $t=1, \ldots, N-1$. Equation (A23) gives one equation in one unknown, namely $M_{t}-M_{t-1}$, given $M_{0}(0)$. Using these equations recursively, using the initial conditions $M_{0}$ found in step a, we can solve for $M_{1}, \ldots, M_{N-1}$.

Step c. Solve for $M_{t}$ for $t \geq N$. Given the initial condition $M_{N-1}$ found in step b, equation (A24) can be used to solve for $M_{t}$ for $t \geq N$.

Steps $a$ through $c$ show that for any given $M_{0}$ there is a unique way to construct an 
equilibrium that support the path of interest rates $\left\{i_{t}^{*}\right\}_{t=0}^{\infty}$.

We now show that for any equilibrium that supports the interest rate sequence $\left\{i_{t}^{*}\right\}_{t=0}^{\infty}$, the distribution of cash $M_{t}(s) / M_{t}$ for $s=0, \ldots, N-1$ for all $t \geq N$ is the same. Using equation (A18) for $t \geq N$ in:

$$
M_{t}(0)=N M_{t}-\sum_{s=1}^{N-1}(1-v(s-1)) M_{t}(s-1),
$$

we obtain:

$$
M_{t}(0)=N M_{t}-\sum_{s=1}^{N-1}(1-v(s-1)) \prod_{k=1}^{s-1} v(k) M_{t-k}(0),
$$

and using equation (A18) we get:

$$
\begin{aligned}
& M_{0}(0) \beta^{t-1} \prod_{j=0}^{t-1}\left(1+i_{j}^{*}\right) \\
= & N M_{t}-\sum_{s=1}^{N-1}(1-v(s-1)) \prod_{k=1}^{s-1} v(k) M_{0}(0) \beta^{t-k-1} \prod_{j=0}^{t-k-1}\left(1+i_{j}^{*}\right),
\end{aligned}
$$

which shows that the path of $M_{t}$ is proportional to $M_{0}(0)$ for $t \geq N$. Finally, equation (A18) implies the path of $M_{t}(s)$ is proportional to $M_{0}(0)$, which establishes the desired result. This in turn immediately implies that $M_{t}(s) / M_{t}=M_{t}^{*}(s) / M_{t}^{*}$ and $M_{t+1} / M_{t}=M_{t+1}^{*} / M_{t}^{*}$, and thus that $c_{t}(s)=c_{t}^{*}(s) P_{t+1} / P_{t}=P_{t+1}^{*} / P_{t}^{*}$ for $t \geq N$.

Finally, the qualification that $M_{0}$ has to be close to $M_{0}^{*}$ ensures that in the values constructed for $M_{t}(0)$ during the periods $t=0, \ldots, N-1$ are all strictly positive. 
Figure 1: Short run negative correlation of $M / c$ and $v$

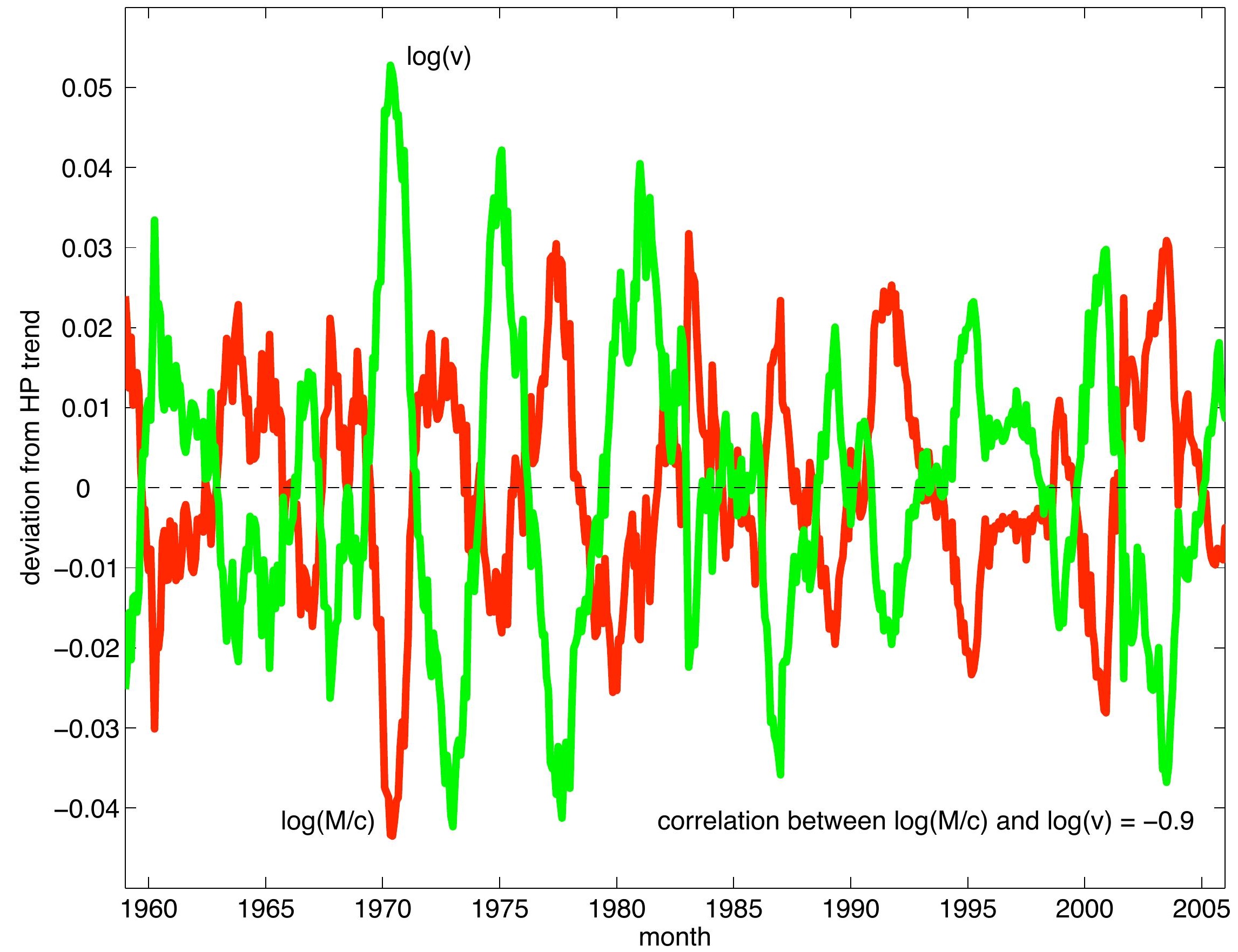


Figure 2: Money up, velocity down, prices sluggish

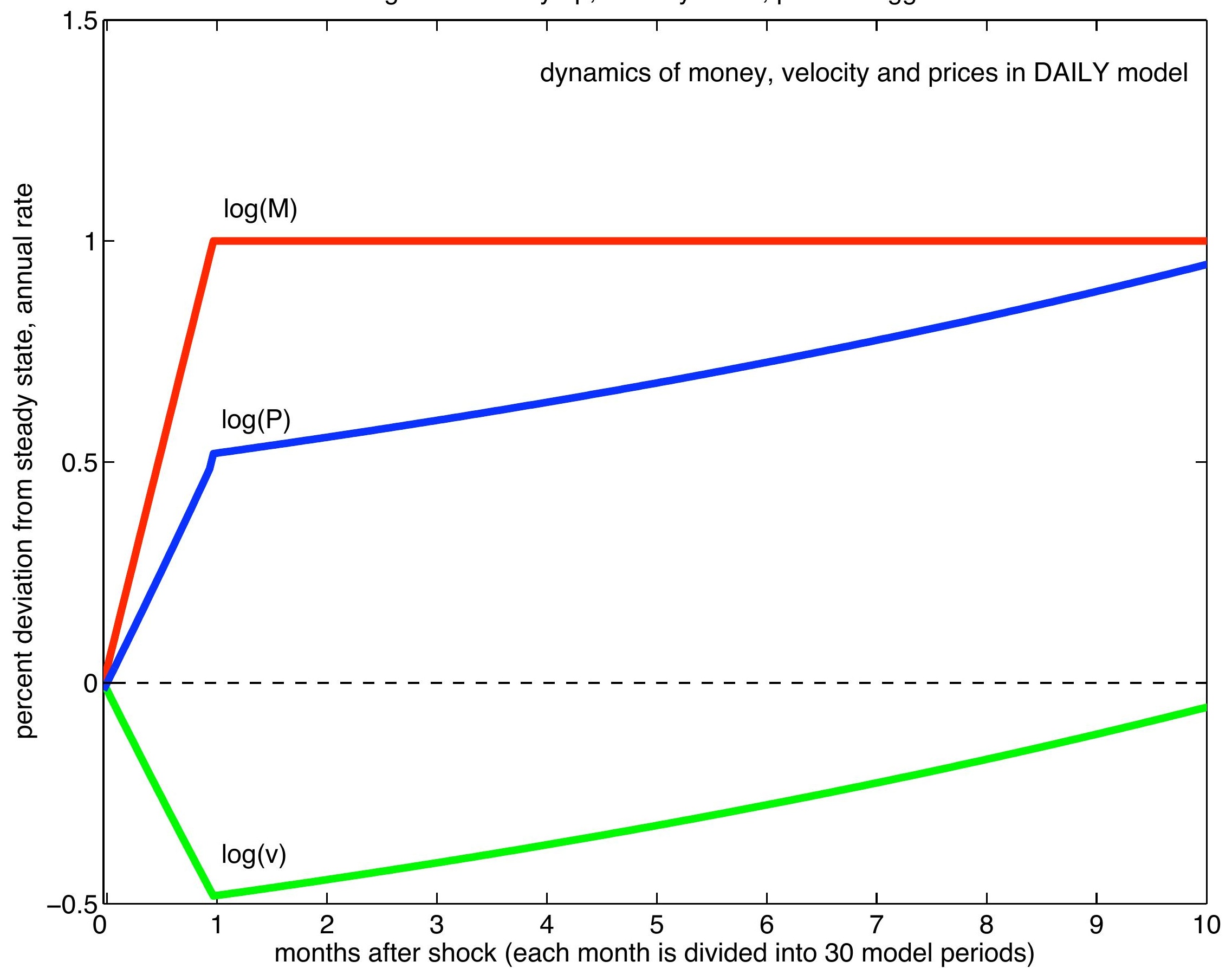


Figure 3: Model and data velocity (deviations from HP trend)

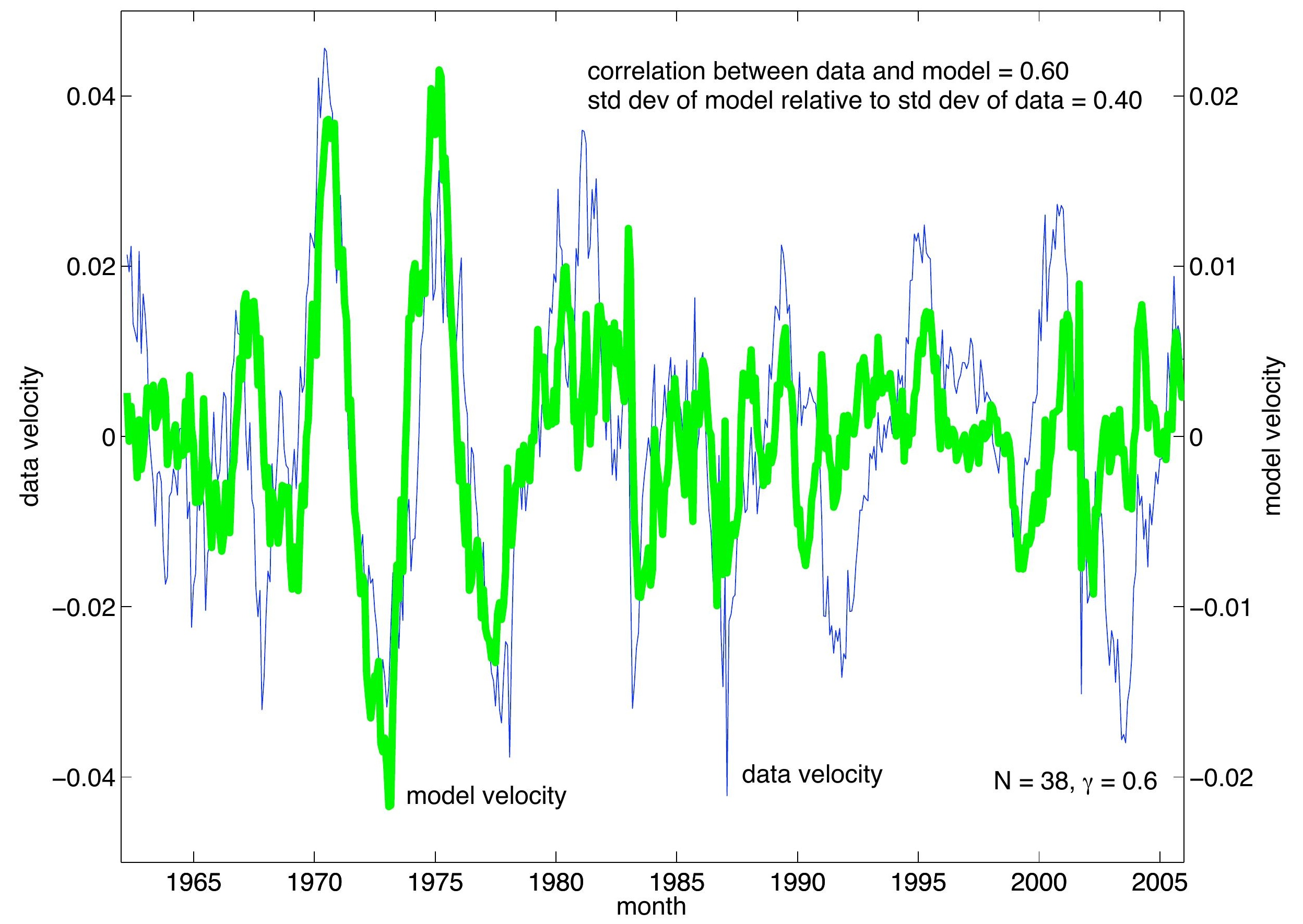


Figure 4: Large liquidity effects

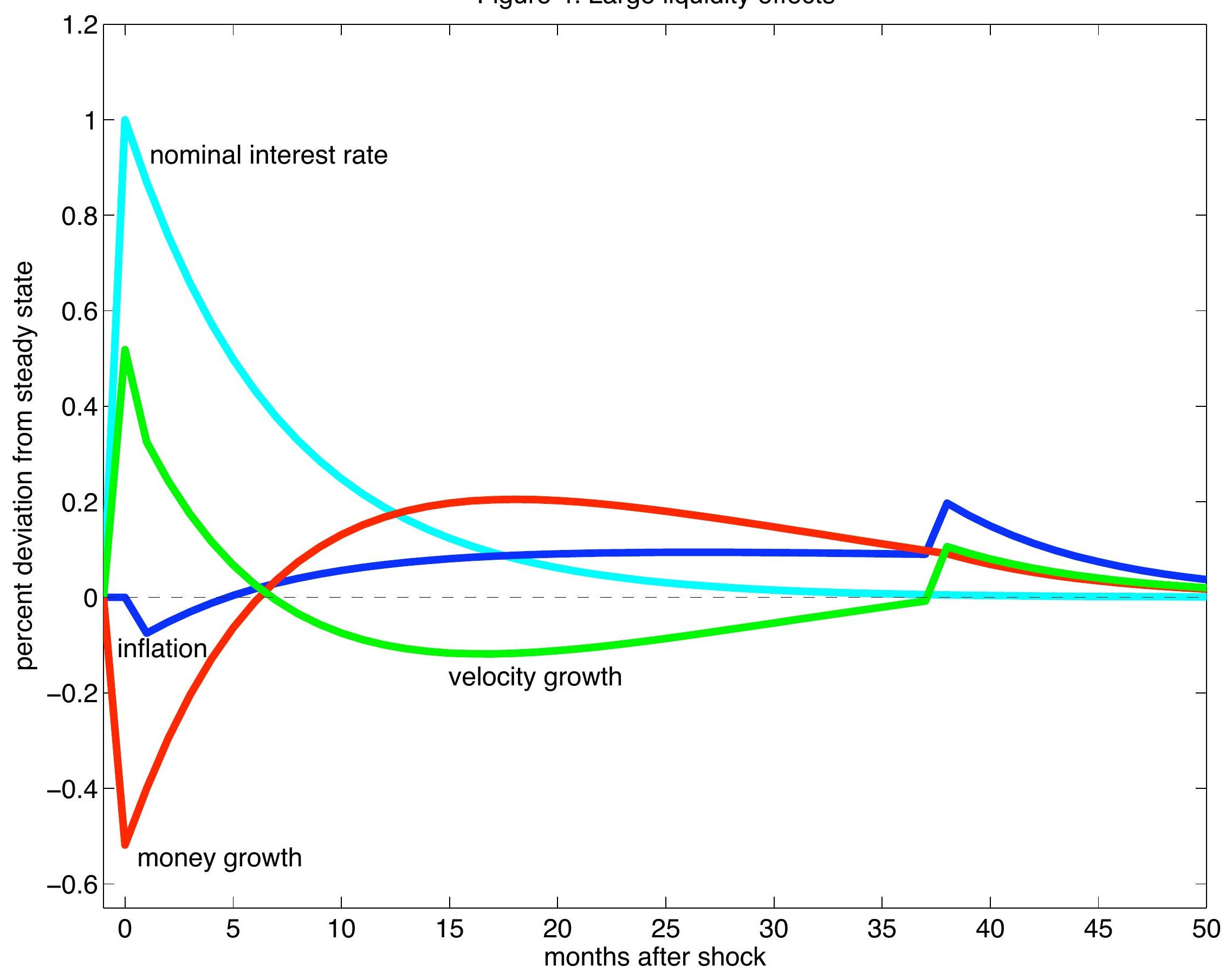


Figure 5: Sluggish price response to persistent interest rate shock

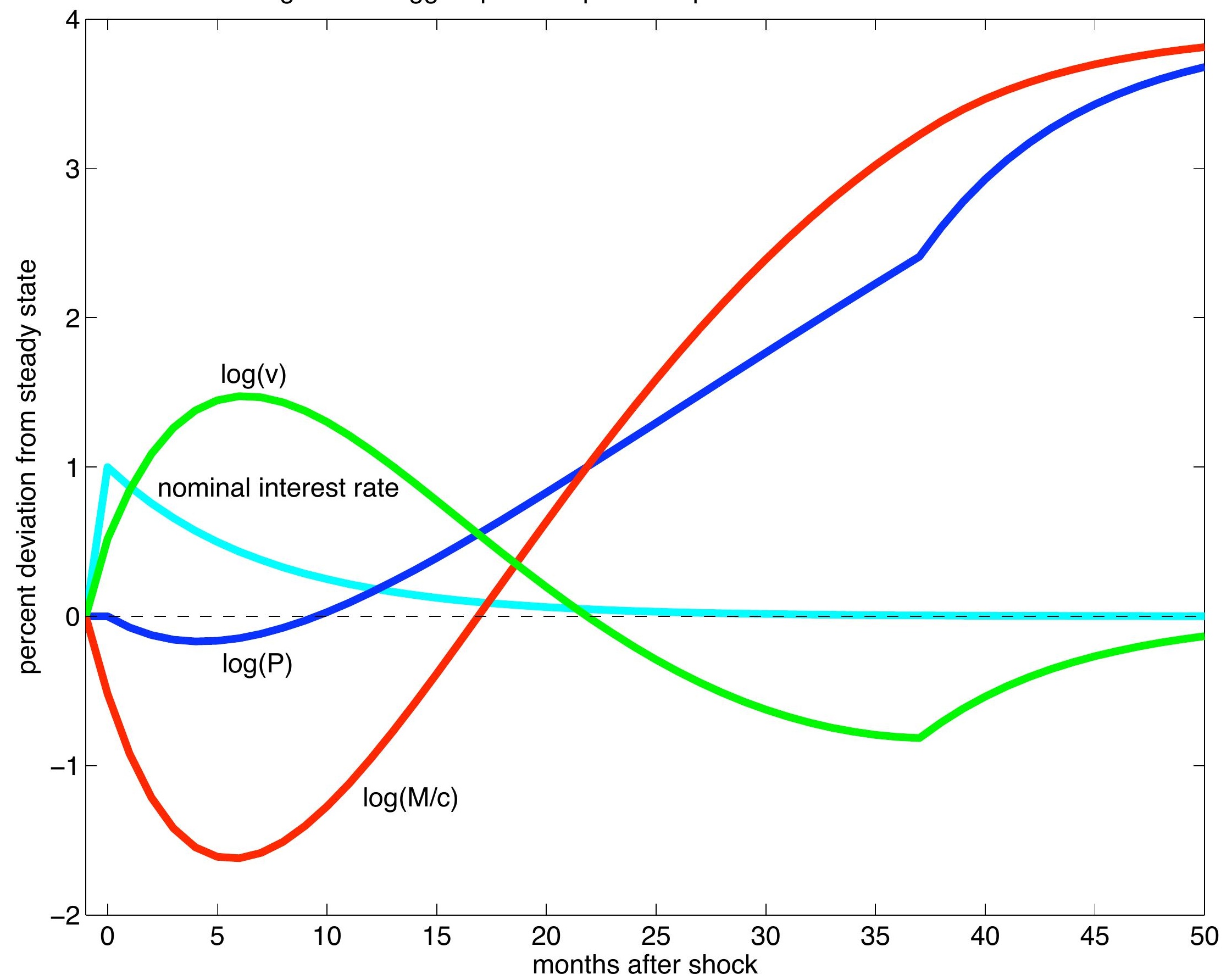

